\title{
Update of the Polar SWIFT model for polar stratospheric ozone loss (Polar SWIFT version 2)
}

\author{
Ingo Wohltmann, Ralph Lehmann, and Markus Rex \\ Alfred Wegener Institute for Polar and Marine Research, Potsdam, Germany \\ Correspondence to: Ingo Wohltmann (ingo.wohltmann@awi.de)
}

Received: 25 January 2017 - Discussion started: 7 March 2017

Revised: 22 May 2017 - Accepted: 8 June 2017 - Published: 13 July 2017

\begin{abstract}
The Polar SWIFT model is a fast scheme for calculating the chemistry of stratospheric ozone depletion in polar winter. It is intended for use in global climate models (GCMs) and Earth system models (ESMs) to enable the simulation of mutual interactions between the ozone layer and climate. To date, climate models often use prescribed ozone fields, since a full stratospheric chemistry scheme is computationally very expensive. Polar SWIFT is based on a set of coupled differential equations, which simulate the polar vortex-averaged mixing ratios of the key species involved in polar ozone depletion on a given vertical level. These species are $\mathrm{O}_{3}$, chemically active chlorine $\left(\mathrm{ClO}_{\mathrm{x}}\right)$, $\mathrm{HCl}, \mathrm{ClONO}_{2}$ and $\mathrm{HNO}_{3}$. The only external input parameters that drive the model are the fraction of the polar vortex in sunlight and the fraction of the polar vortex below the temperatures necessary for the formation of polar stratospheric clouds. Here, we present an update of the Polar SWIFT model introducing several improvements over the original model formulation. In particular, the model is now trained on vortex-averaged reaction rates of the ATLAS Chemistry and Transport Model, which enables a detailed look at individual processes and an independent validation of the different parameterizations contained in the differential equations. The training of the original Polar SWIFT model was based on fitting complete model runs to satellite observations and did not allow for this. A revised formulation of the system of differential equations is developed, which closely fits vortexaveraged reaction rates from ATLAS that represent the main chemical processes influencing ozone. In addition, a parameterization for the $\mathrm{HNO}_{3}$ change by denitrification is included. The rates of change of the concentrations of the chemical species of the Polar SWIFT model are purely chemical rates of change in the new version, whereas in the original Polar
\end{abstract}

SWIFT model, they included a transport effect caused by the original training on satellite data. Hence, the new version allows for an implementation into climate models in combination with an existing stratospheric transport scheme. Finally, the model is now formulated on several vertical levels encompassing the vertical range in which polar ozone depletion is observed. The results of the Polar SWIFT model are validated with independent Microwave Limb Sounder (MLS) satellite observations and output from the original detailed chemistry model of ATLAS.

\section{Introduction}

The importance of interactions between climate change and the ozone layer has long been recognized (e.g., Thompson and Solomon, 2002; Rex et al., 2006; Nowack et al., 2015). Hence, it is desirable to account for these interactions in climate models. Usually, this is accomplished by coupling a full stratospheric chemistry module to a global climate model (GCM) in models referred to as chemistry climate models (CCMs) (e.g., Eyring et al., 2010). Since this approach is computationally expensive, ozone is usually prescribed in the type of climate model runs that are used in the Intergovernmental Panel on Climate Change (IPCC) reports (IPCC, 2013), where long-term runs and multiple scenario runs are required. There is however a growing number of models incorporating interactive ozone chemistry (e.g., Eyring et al., 2013), either by using simplified fast schemes like the Cariolle scheme (Cariolle and Déqué, 1986; Cariolle and Teyssèdre, 2007) or Linoz scheme (McLinden et al., 2000; Hsu and Prather, 2009) or by using CCMs. The fast stratospheric chemistry scheme Polar SWIFT was devel- 
Table 1. List of equations used in the original and new Polar SWIFT version. Terms A to L are specified in Table 2 . 〈...〉 is the vortex mean, $z$ is a free fit parameter. FAP and FAP $_{\mathrm{S}}$ are fractions of the polar vortex below different threshold temperatures for the formation of PSCs (see Sect. 2.5).

\begin{tabular}{|c|c|c|}
\hline Prognostic equations (original) & Prognostic equations (new) & \\
\hline $\mathrm{d}\left\langle\left[\mathrm{O}_{3}\right]\right\rangle / \mathrm{d} t=-D$ & $\mathrm{~d}\left\langle\left[\mathrm{O}_{3}\right]\right\rangle / \mathrm{d} t=-D$ & unchanged \\
\hline $\mathrm{d}\left\langle\left[\mathrm{ClONO}_{2}\right]\right\rangle / \mathrm{d} t=B-A-G-H$ & $\mathrm{~d}\left\langle\left[\mathrm{ClONO}_{2}\right]\right\rangle / \mathrm{d} t=B-A-H$ & \\
\hline $\mathrm{d}\langle[\mathrm{HCl}]\rangle / \mathrm{d} t=C+F-A$ & $\mathrm{~d}\langle[\mathrm{HCl}]\rangle / \mathrm{d} t=C_{1}+C_{2}+F-A-L-K$ & \\
\hline $\mathrm{d}\left\langle\left[\mathrm{HNO}_{3}\right]\right\rangle / \mathrm{d} t=-E$ & $\mathrm{~d}\left\langle\left[\mathrm{HNO}_{3}\right]\right\rangle / \mathrm{d} t=-E$ & unchanged \\
\hline Diagnostic equations (original) & Diagnostic equations (new) & \\
\hline$\left\langle\left[\mathrm{ClO}_{\mathrm{x}}\right]\right\rangle=\left\langle\left[\mathrm{Cl}_{\mathrm{y}}\right]\right\rangle-\langle[\mathrm{HCl}]\rangle-\left\langle\left[\mathrm{ClONO}_{2}\right]\right\rangle$ & $\left\langle\left[\mathrm{ClO}_{\mathrm{x}}\right]\right\rangle=\left\langle\left[\mathrm{Cl}_{\mathrm{y}}\right]\right\rangle-\langle[\mathrm{HCl}]\rangle-\left\langle\left[\mathrm{ClONO}_{2}\right]\right\rangle$ & unchanged \\
\hline$\left\langle\left[\mathrm{HNO}_{3}\right]_{\mathrm{g}}\right\rangle=\left\langle\left[\mathrm{HNO}_{3}\right]\right\rangle \cdot(1-\mathrm{FAP})$ & $\left\langle\left[\mathrm{HNO}_{3}\right]_{\mathrm{g}}\right\rangle=\left\langle\left[\mathrm{HNO}_{3}\right]\right\rangle \cdot\left(1-\mathrm{FAP}_{\mathrm{S}}\right)$ & \\
\hline$+z \cdot\left\langle\left[\mathrm{HNO}_{3}\right]\right\rangle \cdot \mathrm{FAP}$ & $+z \cdot\left\langle\left[\mathrm{HNO}_{3}\right]\right\rangle \cdot \mathrm{FAP}_{\mathrm{s}}$ & \\
\hline
\end{tabular}

oped to enable interactions between climate and the polar ozone layer in time-critical applications of climate models and to improve quality and performance compared to existing schemes. The original version of the Polar SWIFT model was presented in Rex et al. (2014). Here, we present an update of the Polar SWIFT model. The Polar SWIFT model is complemented by an independent model for calculating extrapolar stratospheric ozone chemistry (Extrapolar SWIFT), which is presented in a separate publication (Kreyling et al., 2017).

Polar SWIFT simulates the evolution of the polar vortexaveraged mixing ratios of six key species that are involved in polar ozone depletion by solving a set of coupled differential equations for these species on a given vertical level (Rex et al., 2014). The model includes four prognostic variables $\left(\mathrm{ClONO}_{2}, \mathrm{HCl}\right.$, total $\mathrm{HNO}_{3}$, and $\left.\mathrm{O}_{3}\right)$ and two diagnostic variables (chemically active chlorine $\mathrm{ClO}_{\mathrm{x}}=\mathrm{ClO}+2 \mathrm{Cl}_{2} \mathrm{O}_{2}$ and $\mathrm{HNO}_{3}$ in the gas phase). The differential equations contain several free fit parameters, which were fitted to match satellite observations in the old model version (see Rex et al., 2014) and which are fitted to vortex-averaged reaction rates from the ATLAS Chemistry and Transport Model in the new version.

Polar SWIFT is driven by time series of two external input parameters. The first is the fraction of the polar vortex area that is cold enough to allow for the formation of polar stratospheric clouds (fractional area of PSCs, abbreviated FAP) and the second is the $24 \mathrm{~h}$ average of the fraction of the polar vortex that is exposed to sunlight (fractional area of sunlight, abbreviated FAS). A system of four differential equations is formulated that describes the chemical rate of change of the prognostic variables as a function of FAP, FAS and the mixing ratios of the species only (the term for $\mathrm{HNO}_{3}$ also includes the rate of change caused by denitrification).
The equations comprise terms for the most important chemical processes involved in polar ozone depletion, e.g., the effect of the catalytic $\mathrm{ClO}$ dimer cycle.

Since only a single value per vertical level and species is used in Polar SWIFT, which is constant over the polar vortex, and since the model is able to use a large time step of typically 1 day and a simple integration scheme, it is possible to calculate the ozone evolution of a complete winter in a few seconds.

The original system of equations is shown in Tables 1 and 2, together with the new model formulation, which is presented in more detail in Sect. 3. Table 3 contains the fitted coefficients.

Other fast ozone schemes developed for climate models, such as the Cariolle scheme (Cariolle and Déqué, 1986; Cariolle and Teyssèdre, 2007) or the Linoz scheme (McLinden et al., 2000; Hsu and Prather, 2009), were originally designed to model only extrapolar ozone. In contrast to these schemes, the SWIFT model is not based on a single linear differential equation based on a Taylor series expansion, but on a set of coupled nonlinear differential equations representing the main processes changing polar ozone. This has the advantage that the model is not required to be linear and can cope with the nonlinearities occurring in polar ozone chemistry. Together with the fact that the model equations are closely based on the real atmospheric processes, we expect our model to behave more realistically than a Taylor series based approach, especially in conditions far away from the current atmospheric mean state. The Polar SWIFT model is therefore able to represent ozone-climate interactions during climate change (in combination with the Extrapolar SWIFT model).

The latest version of the Cariolle scheme (Cariolle and Teyssèdre, 2007) also includes a parameterization for hetero- 
geneous polar chemistry, but is based on a quite different approach using a temperature tracer. The newest version of the Linoz scheme (Hsu and Prather, 2009) uses a simple parameterization based on an earlier version of the Cariolle scheme (Cariolle et al., 1990).

In Sect. 2, an overview of the new Polar SWIFT model is given and the fitting procedure is described in detail. In Sect. 3, we present the new differential equations for the four prognostic variables of the model $\left(\mathrm{HCl}, \mathrm{ClONO}_{2}, \mathrm{HNO}_{3}\right.$ and $\mathrm{O}_{3}$ ), and the fits to the modeled reaction rates. In Sect. 4, the Polar SWIFT model is validated by comparison to Microwave Limb Sounder (MLS) satellite data and the original detailed chemistry model of ATLAS. Section 5 contains the conclusions.

\section{Overview of the changes in the new Polar SWIFT version}

\subsection{Revision of the system of differential equations based on ATLAS results}

The original formulation of the system of differential equations is revised based on results of the Lagrangian Chemistry and Transport Model ATLAS. A detailed description of the model can be found in Wohltmann and Rex (2009); Wohltmann et al. (2010). The model includes a gas phase stratospheric chemistry module, heterogeneous chemistry on polar stratospheric clouds and a particle based Lagrangian denitrification module. The chemistry module comprises 47 active species and more than 180 reactions. Absorption cross sections and rate coefficients are taken from recent JPL recommendations (Sander et al., 2011).

Vortex-averaged mixing ratios of all model species and vortex-averaged reaction rates of all modeled reactions are used to identify the important processes involved in polar ozone depletion, and to identify the relevant reactions, their relative importance and their time evolution. Results are based on two model runs for the southern hemispheric winters 2006 and 2011 (1 May to 30 November) and two model runs for the northern hemispheric winters 2004/2005 (15 November to 31 March) and 2009/2010 (1 December to 31 March). The identification of the most important processes and reactions is discussed in a companion paper (Wohltmann et al., 2017). The present paper concentrates on the technical aspects, such as the fitting procedure and finding appropriate parameterizations for the processes.

Details of the model setup are described in Wohltmann et al. (2017) and we will only repeat the most important facts here. Model runs are driven by meteorological data from the ECMWF ERA Interim reanalysis (Dee et al., 2011). Chemical species are mainly initialized by MLS satellite data (Waters et al., 2006). The initial horizontal model resolution is $150 \mathrm{~km}$. The runs use a potential temperature coordinate and vertical motion is driven by total diabatic heating rates from
ERA Interim. In addition to the binary background aerosol, the model simulates three types of polar stratospheric clouds, which are supercooled ternary $\mathrm{HNO}_{3} / \mathrm{H}_{2} \mathrm{SO}_{4} / \mathrm{H}_{2} \mathrm{O}$ solutions (STS), solid clouds composed of nitric acid trihydrate (NAT), and solid ice clouds. The number density of NAT particles in the runs is set to $0.1 \mathrm{~cm}^{-3}$, the number density of ice particles is set to $0.01 \mathrm{~cm}^{-3}$ and the number density of the ternary solution droplets to $10 \mathrm{~cm}^{-3}$. A supersaturation of $\mathrm{HNO}_{3}$ over NAT of 10 (corresponding to about $3 \mathrm{~K}$ supercooling) is assumed to be necessary for the formation of the NAT particles. For ice particles, a supersaturation of 0.35 is assumed. The settings for the polar stratospheric clouds largely favor the formation of liquid clouds (binary liquids and STS clouds) over the formation of NAT clouds, and activation of chlorine predominantly occurs in liquid clouds in the model runs.

\subsection{Vertical levels}

Fitted parameters for the differential equations from Tables 1 and 2 are obtained for five pressure levels, which roughly encompass the vertical range in which ozone depletion is observed. Here, the choice of the pressure levels is guided by the pressure levels of the EMAC (ECHAM/MESSy Atmospheric Chemistry) model (39 level version) in this altitude range (Jöckel et al., 2006; Roeckner et al., 2006), which is the first model in which Polar SWIFT is implemented. The levels used are at approximately 69.7, 54.0, 41.6, 31.8 and $24.1 \mathrm{hPa}$ (see Table 3 for exact values). Results at intermediate levels can either be obtained by vertical interpolation of the fitted parameters or by running the Polar SWIFT model at the two enclosing levels and averaging the results. In the following, we will only show results from the $54 \mathrm{hPa}$ level in the figures for clarity.

\subsection{Fit of the free parameters to ATLAS reaction rates}

The fitting procedure for the original model version was based on fitting the time series of species mixing ratios of a complete Polar SWIFT model run to satellite observations at a given vertical level. This approach has several disadvantages:

- The fit is nonlinear, since the solution of the differential equations depends nonlinearly on the fit parameters. This requires a nonlinear fitting algorithm, which may only find a local and not a global minimum for the residuum of the fit.

- In addition, the fitting procedure is iterative and is computationally more expensive than a linear fit. Every iteration of the fitting procedure requires a complete run of the Polar SWIFT model.

- Transport effects are implicitly included. The rate of change of the satellite data at a given level is the sum of the chemical rate of change and the rate of change by 
Table 2. List of the terms used in the differential equations in the original and new Polar SWIFT version. $\langle\ldots\rangle$ is the vortex mean. $a$ to $l$ and $y$ are free fit parameters. FAP and FAP $\mathrm{S}_{\mathrm{S}}$ are fractions of the polar vortex below different threshold temperatures for the formation of PSCs (see Sect. 2.5). FAS is the fraction of the vortex exposed to sunlight (see Sect.2.5).

\begin{tabular}{|c|c|c|c|}
\hline \multicolumn{2}{|l|}{ Expression (original) } & \multicolumn{2}{|l|}{ Expression (new) } \\
\hline \multicolumn{4}{|c|}{ Term $A$ : heterogeneous reaction $\mathrm{HCl}+\mathrm{ClONO}_{2}$} \\
\hline $\begin{array}{l}a \cdot\left\langle\left[\mathrm{ClONO}_{2}\right]\right\rangle \cdot\left\langle\left[\mathrm{HNO}_{3}\right]\right\rangle \cdot \mathrm{FAP} \\
a \cdot\langle[\mathrm{HCl}]\rangle \cdot\left\langle\left[\mathrm{ClONO}_{2}\right]\right\rangle \cdot\left\langle\left[\mathrm{HNO}_{3}\right]\right\rangle \cdot \mathrm{FAP}\end{array}$ & $\begin{array}{l}\langle[\mathrm{HCl}]\rangle>27 \mathrm{ppt} \\
\langle[\mathrm{HCl}]\rangle<27 \mathrm{ppt}\end{array}$ & $\begin{array}{l}a \cdot\left\langle\left[\mathrm{ClONO}_{2}\right]\right\rangle \cdot\left\langle\left[\mathrm{HNO}_{3}\right]\right\rangle^{2 / 3} \cdot \mathrm{FAP} \\
a \cdot\langle[\mathrm{HCl}]\rangle \cdot\left\langle\left[\mathrm{ClONO}_{2}\right]\right\rangle \cdot\left\langle\left[\mathrm{HNO}_{3}\right]\right\rangle^{2 / 3} \cdot \mathrm{FAP}\end{array}$ & $\begin{array}{l}\langle[\mathrm{HCl}]\rangle>1 \mathrm{ppt} \\
\langle[\mathrm{HCl}]\rangle<1 \mathrm{ppt}\end{array}$ \\
\hline \multicolumn{4}{|c|}{ Term $B$ (and $G$ in the original model): net change by $\mathrm{ClONO}_{2}$ gas phase reactions } \\
\hline $\begin{array}{l}b \cdot\left\langle\left[\mathrm{HNO}_{3}\right]_{\mathrm{g}}\right\rangle \cdot \mathrm{FAS} \\
b \cdot\left\langle\left[\mathrm{ClO}_{\mathrm{X}}\right]\right\rangle \cdot\left\langle\left[\mathrm{HNO}_{3}\right]_{\mathrm{g}}\right\rangle \cdot \mathrm{FAS} \\
g \cdot\left\langle\left[\mathrm{ClONO}_{2}\right]\right\rangle \cdot \mathrm{FAS}\end{array}$ & $\begin{array}{l}\left\langle\left[\mathrm{ClO}_{\mathrm{x}}\right]\right\rangle>135 \mathrm{ppt} \\
\left\langle\left[\mathrm{ClO}_{\mathrm{x}}\right]\right\rangle<135 \mathrm{ppt}\end{array}$ & $b \cdot\left\langle\left[\mathrm{ClO}_{\mathrm{x}}\right]\right\rangle \cdot\left\langle\left[\mathrm{HNO}_{3}\right]_{\mathrm{g}}\right\rangle \cdot \mathrm{FAS}$ & $\begin{array}{l}B \text { and } G \\
\text { replaced by } B\end{array}$ \\
\hline \multicolumn{4}{|c|}{ Term $C$ : reaction $\mathrm{Cl}+\mathrm{CH}_{4}$} \\
\hline$c \cdot\left\langle\left[\mathrm{ClO}_{\mathrm{x}}\right]\right\rangle /\left\langle\left[\mathrm{O}_{3}\right]\right\rangle \cdot \mathrm{FAS}$ & & $\begin{array}{l}c_{1} \cdot\left\langle\left[\mathrm{ClO}_{\mathrm{x}}\right]\right\rangle /\left\langle\left[\mathrm{O}_{3}\right]\right\rangle \cdot \mathrm{FAS}^{2}+ \\
c_{2} \cdot\left\langle\left[\mathrm{ClONO}_{2}\right]\right\rangle /\left\langle\left[\mathrm{O}_{3}\right]\right\rangle \cdot \mathrm{FAS}^{3}\end{array}$ & \\
\hline \multicolumn{4}{|c|}{ Term $D$ : ozone depletion by $\mathrm{ClO}$ dimer and $\mathrm{ClO}-\mathrm{BrO}$ cycle } \\
\hline$d \cdot\left\langle\left[\mathrm{ClO}_{\mathrm{X}}\right]\right\rangle \cdot \mathrm{FAS}$ & & $d \cdot\left\langle\left[\mathrm{ClO}_{\mathrm{x}}\right]\right\rangle \cdot \mathrm{FAS}$ & unchanged \\
\hline \multicolumn{4}{|c|}{ Term $E$ : denitrification } \\
\hline$e \cdot\left\langle\left[\mathrm{HNO}_{3}\right]\right\rangle \cdot \max ((\mathrm{FAP}-y), 0)$ & & $e \cdot\left\langle\left[\mathrm{HNO}_{3}\right]\right\rangle \cdot \mathrm{FAP}_{\mathrm{s}}$ & \\
\hline \multicolumn{4}{|c|}{ Term $F$ : reaction $\mathrm{ClO}+\mathrm{OH}$} \\
\hline $\begin{array}{l}f \cdot\left\langle\left[\mathrm{ClO}_{\mathrm{x}}\right]\right\rangle \cdot \mathrm{FAS}^{2} \\
0.25 f \cdot\left\langle\left[\mathrm{ClO}_{\mathrm{x}}\right]\right\rangle \cdot \mathrm{FAS}^{2}\end{array}$ & $\begin{array}{l}\text { Arctic } \\
\text { Antarctic }\end{array}$ & $f \cdot\left\langle\left[\mathrm{ClO}_{\mathrm{x}}\right]\right\rangle \cdot \mathrm{FAS}^{2}$ & \\
\hline \multicolumn{4}{|c|}{ Term $H$ : heterogeneous reaction $\mathrm{ClONO}_{2}+\mathrm{H}_{2} \mathrm{O}$} \\
\hline$h \cdot\left\langle\left[\mathrm{ClONO}_{2}\right]\right\rangle \cdot \max ((\mathrm{FAP}-y), 0)$ & & $h \cdot\left\langle\left[\mathrm{ClONO}_{2}\right]\right\rangle \cdot\left\langle\left[\mathrm{HNO}_{3}\right]\right\rangle^{2 / 3} \cdot \mathrm{FAP}$ & \\
\hline \multicolumn{4}{|c|}{ Term $K$ : reaction $\mathrm{HCl}+\mathrm{OH}$} \\
\hline \multicolumn{4}{|c|}{$k \cdot\langle[\mathrm{HCl}]\rangle \cdot \mathrm{FAS}^{2}$} \\
\hline \multicolumn{4}{|c|}{ Term $L$ : heterogeneous reaction $\mathrm{HOCl}+\mathrm{HCl}$} \\
\hline & & $\begin{array}{l}l \cdot\langle[\mathrm{HOCl}]\rangle \cdot\langle[\mathrm{HCl}]\rangle \cdot\left\langle\left[\mathrm{HNO}_{3}\right]\right\rangle^{2 / 3} \cdot \mathrm{FAP} \\
\langle[\mathrm{HOCl}]\rangle=\left\langle\left[\mathrm{ClO}_{\mathrm{x}}\right]\right\rangle \cdot \mathrm{FAS}\end{array}$ & \\
\hline
\end{tabular}

Table 3. Fit coefficients.

\begin{tabular}{lllllll}
\hline $\begin{array}{l}p \\
{[\mathrm{hPa}]}\end{array}$ & 69.66111 & 54.03643 & 41.59872 & 31.77399 & 24.07468 & $\begin{array}{l}\text { Scaling } \\
\text { factor }\end{array}$ \\
\hline$a$ & 7.986612 & 4.085210 & 2.846390 & 2.479554 & 1.963608 & $\times 10^{4}$ \\
$b$ & 3.473857 & 3.031378 & 2.740275 & 2.715443 & 3.770580 & $\times 10^{7}$ \\
$c_{1}$ & 0.894648 & 0.836649 & 0.706846 & 0.716972 & 1.108429 & $\times 10^{-6}$ \\
$c_{2}$ & 5.566789 & 6.386807 & 6.274739 & 5.244277 & 4.904797 & $\times 10^{-7}$ \\
$d$ & 8.884890 & 8.325397 & 7.646982 & 6.904189 & 6.515611 & $\times 10^{1}$ \\
$e$ & 3.846921 & 4.124637 & 4.285359 & 4.443291 & 3.918175 & $\times 10^{-2}$ \\
$f$ & 1.863004 & 1.817837 & 1.804207 & 1.940491 & 3.163943 & $\times 10^{-1}$ \\
$h$ & 1.030654 & 0.795576 & 0.592115 & 0.500293 & 0.582744 & $\times 10^{4}$ \\
$k$ & 0.513798 & 0.553199 & 0.654543 & 0.843783 & 1.219857 & $\times 10^{-1}$ \\
$l$ & 2.242523 & 1.176265 & 0.646520 & 0.351599 & 0.185954 & $\times 10^{14}$ \\
$z$ & 6.788512 & 7.265396 & 7.569032 & 7.615205 & 7.179308 & $\times 10^{-1}$ \\
\hline
\end{tabular}

transport. Hence, the fit parameters include a transport effect. This effect is most pronounced for $\mathrm{O}_{3}$, where the rates of chemical change and of change by subsidence in the polar vortex are comparable.
- Satellite data of the species that are fitted have to be available. For species like $\mathrm{ClONO}_{2}$, the availability of measurements is limited. 
Here, we employ a new method that avoids these disadvantages. We take advantage of the fact that all of the equations of the system of differential equations from Tables 1 and 2 on a given vertical level are of the form

$$
\begin{aligned}
\frac{\mathrm{d}\left\langle X_{n}\right\rangle\left(t_{i}\right)}{\mathrm{d} t} & =c_{p_{n 1}} f_{p_{n 1}}\left(\left\langle X_{1}\right\rangle\left(t_{i}\right), \ldots,\left\langle X_{N}\right\rangle\left(t_{i}\right), t_{i}\right)+\ldots \\
& +c_{p_{n M(n)}} f_{p_{n M(n)}}\left(\left\langle X_{1}\right\rangle\left(t_{i}\right), \ldots,\left\langle X_{N}\right\rangle\left(t_{i}\right), t_{i}\right),
\end{aligned}
$$

where $\langle\ldots\rangle$ is the vortex average, $\left\langle X_{n}\right\rangle$ is the vortex-averaged mixing ratio of species $n$ and $N$ is the number of species $(n=1, \ldots, N)$. The $f_{p}(\ldots)$ are functions of the mixing ratios (and of fixed parameters such as FAS and FAP), which represent the parameterizations for the different processes $p=1, \ldots, P$ introduced in Rex et al. (2014). The processes $f_{p}$ are the terms $A, B$, etc., in Tables 1 and 2 . The $c_{p}$ are the associated fitted coefficients for each parameterization ( $a$, $b$, etc., in Table 2). The $p_{n m}$ assign a parameterization to a specific species $n$ and the additive term $m$ of that species. $M(n)$ is the number of additive terms for species $n$. Different $p_{n m}$ are allowed to contain the same number (i.e., the same parameterization can be used for different species). The net chemical rate of change $\mathrm{d}\left\langle X_{n}\right\rangle\left(t_{i}\right) / \mathrm{d} t$ for every species and all $f_{p}(\ldots)$ terms can be obtained as fixed values from the ATLAS runs for a number of model time steps $t_{i}(i=1, \ldots, T)$, since both the vortex-averaged mixing ratios and the vortexaveraged reaction rates are available from the ATLAS model. This gives a system of $T \cdot N$ equations that can be solved for the $c_{p}$. The system consists of simple linear equations for the $c_{p}$, which can be solved by a least-squares fit (since the number of equations $T \cdot N$ is much larger than the number of coefficients $P$, the system is overdetermined). Equations with different time steps $t_{i}$ but the same species $n$ are coupled since they contain the same $c_{p}$. Additionally, equations with different species may also contain the same $c_{p}$.

To simplify the fit further, we split the left-hand side into a sum of the rates of change that are caused by single chemical reactions

$$
\frac{\mathrm{d}\left\langle X_{n}\right\rangle}{\mathrm{d} t}\left(t_{i}\right)=\left.\frac{\mathrm{d}\left\langle X_{n}\right\rangle}{\mathrm{d} t}\right|_{1}\left(t_{i}\right)+\ldots+\left.\frac{\mathrm{d}\left\langle X_{n}\right\rangle}{\mathrm{d} t}\right|_{K(n)}\left(t_{i}\right),
$$

where $\mathrm{d}\left\langle X_{n}\right\rangle /\left.\mathrm{d} t\right|_{k}$ is the rate of change caused by the $k$ th reaction changing species $n$ in ATLAS, with $K(n)$ the number of reactions changing species $n(k=1, \ldots, K(n))$. In many cases, it is feasible to assign a single reaction (or a sum of a very few reactions) to one of the parameterizations $f_{p}(\ldots)$ on the right-hand side. This way, the system of differential equations decouples into many independent linear equations, which can simply be solved by fitting the $c_{p}$ as a factor that scales the parameterization $f_{p}(\ldots)$ to the rate of change of the corresponding chemical reaction:

$$
\left.\frac{\mathrm{d}\left\langle X_{n}\right\rangle}{\mathrm{d} t}\right|_{k}\left(t_{i}\right)=c_{p} f_{p}\left(\left\langle X_{1}\right\rangle\left(t_{i}\right), \ldots,\left\langle X_{N}\right\rangle\left(t_{i}\right), t_{i}\right) .
$$

The time series of the northern hemispheric runs and of the southern hemispheric runs are concatenated and fitted at the same time to obtain one set of fit parameters valid for both hemispheres. This is done because the physical and chemical foundations are the same in both hemispheres and the same parameterizations can be used. Since the conditions in the Northern and Southern hemispheres cover a wide range of temperatures, this approach ensures that the model does respond correctly to changes in temperature, e.g., temperature trends caused by climate change.

\subsection{Vortex averages}

The vortex-averaged mixing ratios of the species $\left\langle X_{n}\right\rangle$ in the Northern Hemisphere are obtained by assuming that the vortex edge is situated at the $36 \mathrm{PVU}$ contour of modified potential vorticity (PV) at all altitudes. Modified PV is calculated according to Lait (1994), with $\theta_{0}=475 \mathrm{~K}$. In the Southern Hemisphere, the vortex edge is assumed to be situated at the -36 PVU contour. Note that the vortex tracer criterion described in Wohltmann et al. (2017) is not applied here.

The air parcels of ATLAS that are inside the vortex are vertically binned into bins centered at the five pressure levels of Polar SWIFT to obtain the mixing ratios $\left\langle X_{n}\right\rangle$ for these levels by averaging. The edges of the bins are in the middle between the Polar SWIFT levels (in the logarithm of pressure). ATLAS model output is available at 00:00 and 12:00 UTC. Vortex means from 00:00 and 12:00 UTC on a given day are averaged to obtain daily means. Vortex-averaged reaction rates are calculated as $24 \mathrm{~h}$ averages over the diurnal cycle by the method described in Wohltmann et al. (2017).

Usually, it is easy to find a parameterization for the rate of a specified reaction or the mixing ratios of a chemical equilibrium if only looking at a given location inside the vortex (i.e., a reaction $A+B \rightarrow C$ leads to the equation $\mathrm{d}[C] / \mathrm{d} t=k[A][B]$ with $[A]$ the mixing ratio of $A$ and $k$ the rate coefficient). However, problems arise if vortex averages are used. If we assume that either the mixing ratios of the species are sufficiently constant over the area of the vortex, or that the differential equations do only contain terms linear in the mixing ratios, we can use vortex averages. Care has to be taken if products of mixing ratios appear in the equations. If $X_{1}$ and $X_{2}$ are the mixing ratios of two species, the vortex average of the product is not necessarily the same as the product of the vortex averages (if their covariance is not zero)

$\left\langle X_{1} X_{2}\right\rangle=\left\langle X_{1}\right\rangle\left\langle X_{2}\right\rangle+\operatorname{cov}\left(X_{1}, X_{2}\right)$.

There are several possibilities to cope with this problem. If at least one of the species is long-lived and constant over the vortex, approximate equality can be assumed. If both species are short-lived, the vortex can be divided into a sunlit part and a dark part, and two separate constant mixing ratios have to be assumed in the sunlit and dark part.

However, we will see in the following that it is not possible in all cases to transform the original expression for the chemical reaction at a single location to an equivalent expression 
that only uses vortex averages. We use expressions that are empirically derived in these cases. Here, the quality of the approximation is assessed by the goodness of fit for the wide range of climate conditions observed in the training data set.

\subsection{The external parameters FAP and FAS}

The $24 \mathrm{~h}$ averaged fraction of the polar vortex in sunlight (FAS) and the fraction of the polar vortex below the formation temperature of polar stratospheric clouds (FAP) are calculated from the same ERA Interim data that is used for running the ATLAS model for consistency.

Two different FAP parameters are used in the new version of the Polar SWIFT model, which are called FAP and $\mathrm{FAP}_{\mathrm{s}}$. Evidence from modeling studies and observations suggests that a considerable part of chlorine activation occurs on clouds composed of liquid binary and supercooled ternary solutions (STS) and that nitric acid trihydrate (NAT) clouds only form when large supersaturations of more than 10 are reached (for a detailed discussion and references, see Wohltmann et al., 2013). By chance, the required supercooling of $3 \mathrm{~K}$ also corresponds roughly to the temperature at which binary liquid aerosols begin to take up $\mathrm{HNO}_{3}$ in significant quantities and are transformed into ternary solutions, which increases the reaction rates on liquid aerosols significantly. Hence, we calculate the area of the polar vortex above a supersaturation of $\mathrm{HNO}_{3}$ over NAT of 10 according to the equations of Hanson and Mauersberger (1988) and divide the values by the vortex area. This quantity is called FAP in the following. However, chlorine activation already sets in at higher temperatures than the NAT threshold temperature minus $3 \mathrm{~K}$ on the liquid aerosols, albeit with smaller rates. Hence, we also calculate a quantity called FAP by assuming no supersaturation. The decision to use FAP or FAP is $_{\mathrm{s}}$ based empirically on the quality of the fit for the single equations. A special case is the denitrification, which is based on sedimenting NAT particles in the ATLAS model and is parameterized with FAP $_{s}$.

For FAS, the area below a solar zenith angle of $90^{\circ}$ inside the vortex is calculated and divided by the vortex area. To obtain a $24 \mathrm{~h}$ average, the polar vortex obtained from ERA Interim is assumed to be fixed for a virtual $24 \mathrm{~h}$ period. Then, the solar zenith angles are calculated for many intermediate time steps in this $24 \mathrm{~h}$ period. The area below $90^{\circ}$ solar zenith angle is calculated for each intermediate step. Finally, the results are averaged over the intermediate time steps.

\section{The parameterizations}

In the next sections, we present the new differential equations for the four prognostic variables of the model $\left(\mathrm{HCl}, \mathrm{ClONO}_{2}\right.$, $\mathrm{HNO}_{3}$ and $\mathrm{O}_{3}$ ), and the fits to the modeled reaction rates. The terms $f_{p}$ are indicated by upper case letters $A, B$, $C$, etc., in the following, to comply with the notation in Rex et al.
(2014). Mixing ratios of species are denoted by putting the name of the species into brackets, e.g., $[\mathrm{HCl}]$ for the mixing ratio of $\mathrm{HCl} .\langle\ldots\rangle$ is the vortex mean again.

\section{$3.1 \mathrm{HCl}$}

\subsubsection{Overview}

The equation for $\mathrm{HCl}$ is changed from

$\frac{\mathrm{d}\langle[\mathrm{HCl}]\rangle}{\mathrm{d} t}=C+F-A$

in the original model to

$\frac{\mathrm{d}\langle[\mathrm{HCl}]\rangle}{\mathrm{d} t}=C_{1}+C_{2}+F-A-L-K$

in the new model. Term $C$ of the original model and terms $C_{1}$ and $C_{2}$ of the new model represent the effect of the reaction

$\mathrm{Cl}+\mathrm{CH}_{4} \rightarrow \mathrm{HCl}+\mathrm{CH}_{3}$,

which is responsible for deactivation of $\mathrm{Cl}$ into $\mathrm{HCl}$ under ozone hole conditions in the Southern Hemisphere and is the main $\mathrm{HCl}$ production reaction in both hemispheres. In the new parameterization, we split term $C$ into two terms $C_{1}$ and $C_{2}$ to account for two different $\mathrm{Cl}$ sources $\left(\mathrm{Cl}_{2} \mathrm{O}_{2}\right.$ photolysis and the $\mathrm{ClO}+\mathrm{NO}$ reaction). The less important reaction

$\mathrm{Cl}+\mathrm{CH}_{2} \mathrm{O}+\mathrm{O}_{2} \rightarrow \mathrm{HCl}+\mathrm{CO}+\mathrm{HO}_{2}$,

which also depends on $\mathrm{Cl}$, is subsumed into term $C$ in the new model. Term $F$ represents the effect of the reaction of $\mathrm{ClO}$ with $\mathrm{OH}$

$\mathrm{ClO}+\mathrm{OH} \rightarrow \mathrm{HCl}+\mathrm{O}_{2}$,

which helps $\mathrm{HCl}$ reformation in both hemispheres. Term $A$ accounts for the effect of the most important heterogeneous reaction activating chlorine

$\mathrm{HCl}+\mathrm{ClONO}_{2} \rightarrow \mathrm{Cl}_{2}+\mathrm{HNO}_{3}$.

We introduce a new term $L$ for the heterogenous reaction

$\mathrm{HOCl}+\mathrm{HCl} \rightarrow \mathrm{Cl}_{2}+\mathrm{H}_{2} \mathrm{O}$,

which is responsible for a considerable part of the activation in the Southern Hemisphere and for a non-negligible part in the Northern Hemisphere. Another reaction that consumes $\mathrm{HCl}$ not included in the original model that turned out to be significant in late winter and spring is

$\mathrm{HCl}+\mathrm{OH} \rightarrow \mathrm{H}_{2} \mathrm{O}+\mathrm{Cl}$,

which is considered by a new term $K$. 


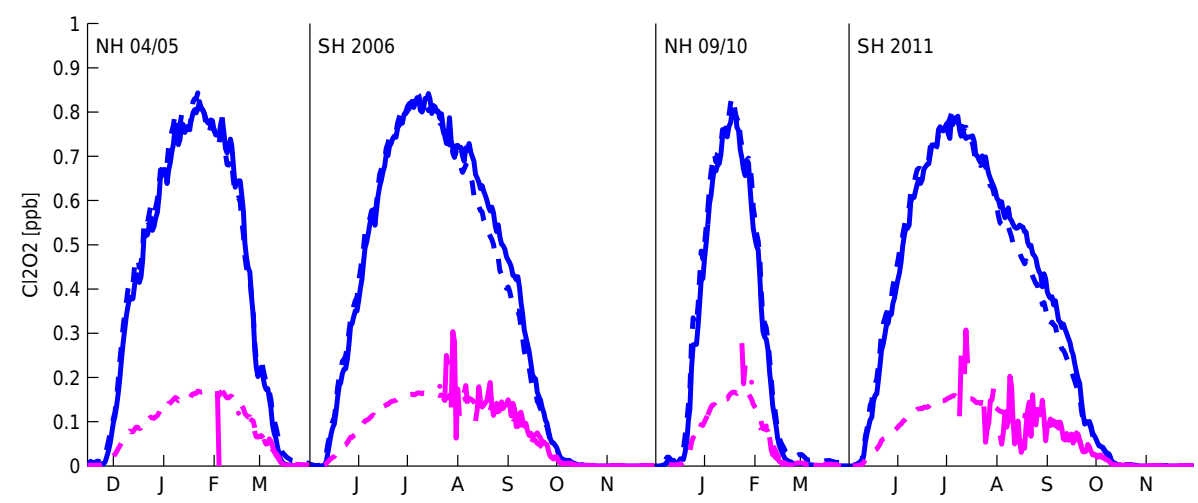

Figure 1. Vortex-averaged mixing ratio of $\mathrm{Cl}_{2} \mathrm{O}_{2}$ for the Arctic winter 2004/2005, the Antarctic winter 2006, the Arctic winter 2009/2010 and the Antarctic winter 2011 at $54 \mathrm{hPa}$ (from left to right). Vortex average (solid blue) and parameterization for the mixing ratio by $\left\langle\left[\mathrm{ClO} \mathrm{x}_{\mathrm{x}}\right]\right\rangle(1-$ FAS) (dashed blue) and average over sunlit part of vortex (solid magenta) and parameterization for the mixing ratio by $\left\langle\left[\mathrm{ClO}_{\mathrm{x}}\right]\right\rangle$ (dashed magenta). Tick marks on the horizontal axis show start of months.

\subsubsection{Term $C$}

Term $C$ represents the effect of

$\mathrm{Cl}+\mathrm{CH}_{4} \rightarrow \mathrm{HCl}+\mathrm{CH}_{3}$.

This reaction is responsible for chlorine deactivation under ozone hole conditions and is the main production reaction of $\mathrm{HCl}$ in both hemispheres (Wohltmann et al., 2017). If we assume that $\mathrm{CH}_{4}$ is sufficiently constant, the rate of production of $\mathrm{HCl}$ by this reaction is only proportional to $\mathrm{Cl}$ :

$\left\langle\left.\frac{\mathrm{d}[\mathrm{HCl}]}{\mathrm{d} t}\right|_{\mathrm{R} 1}\right\rangle \sim\langle[\mathrm{Cl}]\rangle$

Term $C$ of the original model is split into two additive terms $C=C_{1}+C_{2}$ in the new model. These two terms account for two different sources of $\mathrm{Cl}$. Under sunlit conditions, $\mathrm{Cl}$ is mainly determined by two source reactions that produce $\mathrm{Cl}$

$\mathrm{Cl}_{2} \mathrm{O}_{2}+h v \rightarrow 2 \mathrm{Cl}+\mathrm{O}_{2}$

$\mathrm{ClO}+\mathrm{NO} \rightarrow \mathrm{Cl}+\mathrm{NO}_{2}$

and a reaction that removes $\mathrm{Cl}$

$\mathrm{Cl}+\mathrm{O}_{3} \rightarrow \mathrm{ClO}+\mathrm{O}_{2}$.

Reaction (R7) is coupled to the catalytic $\mathrm{ClO}$ dimer cycle. It can be shown by using the equilibrium condition $\mathrm{d}[\mathrm{Cl}] / \mathrm{d} t=0$ that the mixing ratio of $\mathrm{Cl}$ under sunlit conditions is roughly approximated by

$$
\langle[\mathrm{Cl}]\rangle_{\text {day }}=\left\langle\frac{2 k_{\mathrm{R} 7}\left[\mathrm{Cl}_{2} \mathrm{O}_{2}\right]}{k_{\mathrm{R} 9}\left[\mathrm{O}_{3}\right]}\right\rangle_{\text {day }}+\left\langle\frac{k_{\mathrm{R} 8}[\mathrm{ClO}][\mathrm{NO}]}{k_{\mathrm{R} 9}\left[\mathrm{O}_{3}\right]}\right\rangle_{\text {day }},
$$

where $\langle\ldots\rangle_{\text {day }}$ is the average over the sunlit part of the vortex and the $k_{\mathrm{R}}$ are the rate coefficients. The first term on the right side corresponds to term $C$ for the $\mathrm{Cl}_{2} \mathrm{O}_{2}$ photolysis in the original model and to term $C_{1}$ in the new model. The second term corresponds to the new term $C_{2}$ for the $\mathrm{ClO}+\mathrm{NO}$ reaction. Vortex-averaged mixing ratios can be obtained by an area-weighted average

$$
\begin{aligned}
\langle[\mathrm{Cl}]\rangle & \approx \mathrm{FAS} \cdot\langle[\mathrm{Cl}]\rangle_{\text {day }}+(1-\mathrm{FAS}) \cdot\langle[\mathrm{Cl}]\rangle_{\text {night }} \\
& \approx \mathrm{FAS} \cdot\langle[\mathrm{Cl}]\rangle_{\text {day }}
\end{aligned}
$$

under the assumption that there is no $\mathrm{Cl}$ at night.

\section{Term $C_{1}$}

The vortex average of the photolysis coefficient $k_{\mathrm{R} 7}$ is assumed to be proportional to FAS. Figure 1 shows that $\left\langle\left[\mathrm{Cl}_{2} \mathrm{O}_{2}\right]\right\rangle_{\text {day }}$ is proportional to $\left\langle\left[\mathrm{ClO}_{\mathrm{x}}\right]\right\rangle$ in good approximation, since a relatively constant fraction of $\mathrm{ClO}_{\mathrm{x}}$ is in the form of $\mathrm{Cl}_{2} \mathrm{O}_{2}$ during day in the covered time period. We assume that ozone is sufficiently constant over the vortex so that $\left\langle\left[\mathrm{O}_{3}\right]\right\rangle_{\text {day }}=\left\langle\left[\mathrm{O}_{3}\right]\right\rangle$ and that the division and the vortex mean can be interchanged. Hence, term $C_{1}$ is parameterized similarly as the original term $C$

$C_{1}=c_{1} \cdot\left\langle\left[\mathrm{ClO}_{\mathrm{x}}\right]\right\rangle /\left\langle\left[\mathrm{O}_{3}\right]\right\rangle \cdot \mathrm{FAS}^{2}$.

This is the original term multiplied by FAS. The two different FAS factors in the new model have their origin in the areaweighted average and in the photolysis coefficient, respectively. The term $1 /\left\langle\left[\mathrm{O}_{3}\right]\right\rangle$ makes sure that if ozone concentrations become low, Reaction (R9) of the $\mathrm{ClO}$ dimer cycle becomes less efficient and the ratio of $\mathrm{Cl}$ over $\mathrm{ClO}$ increases.

\section{Term $C_{2}$}

Term $C_{2}$ accounts for Reaction (R8), which produces $\mathrm{Cl}$ in large quantities in spring (Wohltmann et al., 2017) and was not considered in the original model. Looking at Eq. (8), it is tempting to model term $C_{2}$ by assuming that

$\left\langle\frac{[\mathrm{ClO}][\mathrm{NO}]}{\left[\mathrm{O}_{3}\right]}\right\rangle_{\text {day }}$ 


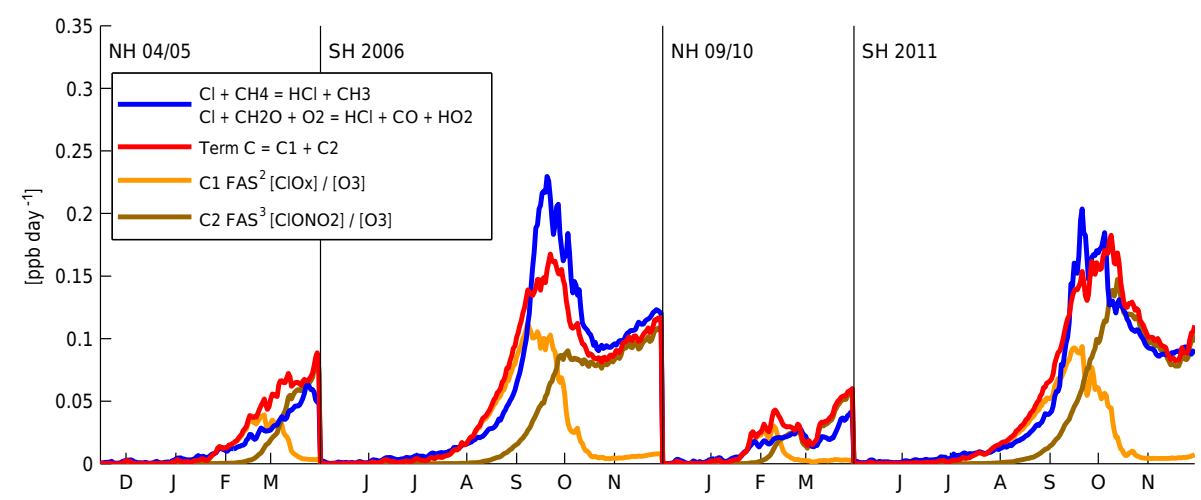

Figure 2. Fit of term $C$ for the Arctic winter 2004/2005, the Antarctic winter 2006, the Arctic winter 2009/2010 and the Antarctic winter 2011 at $54 \mathrm{hPa}$. Sum of the vortex-averaged reaction rates modeled by ATLAS for the reactions $\mathrm{Cl}+\mathrm{CH}_{4}$ and $\mathrm{Cl}+\mathrm{CH}_{2} \mathrm{O}$ (blue), the fitted terms $C_{1}$ (orange) and $C_{2}$ (brown) and the sum $C_{1}+C_{2}$ (red). Tick marks on the horizontal axis show start of months.

is equal to

$$
\frac{\langle[\mathrm{ClO}]\rangle_{\text {day }}\langle[\mathrm{NO}]\rangle_{\text {day }}}{\left\langle\left[\mathrm{O}_{3}\right]\right\rangle_{\text {day }}}
$$

and then finding parameterizations for $\langle[\mathrm{ClO}]\rangle_{\text {day }},\langle[\mathrm{NO}]\rangle_{\text {day }}$ and $\left\langle\left[\mathrm{O}_{3}\right]\right\rangle_{\text {day }}$. Unfortunately, it turns out that this approximation is not valid, since the spatial distributions of $\mathrm{ClO}$ and $\mathrm{NO}$ are very different and

$$
\langle[\mathrm{ClO}][\mathrm{NO}]\rangle_{\text {day }} \neq\langle[\mathrm{ClO}]\rangle_{\text {day }}\langle[\mathrm{NO}]\rangle_{\text {day }} .
$$

The reason is that there is an equilibrium between $\mathrm{ClONO}_{2}$ on the one side and $\mathrm{ClO}$ and $\mathrm{NO}_{2}$ on the other side, which limits the amount of $\mathrm{ClO}$ and $\mathrm{NO}_{2}$ (and in turn $\mathrm{NO}$ ) that can exist at the same location. $\mathrm{ClONO}_{2}$ is to a good approximation in an equilibrium between

$$
\begin{aligned}
\mathrm{ClONO}_{2}+h v & \rightarrow \mathrm{Cl}+\mathrm{NO}_{3} \\
& \rightarrow \mathrm{ClO}+\mathrm{NO}_{2}
\end{aligned}
$$

and

$\mathrm{ClO}+\mathrm{NO}_{2}+\mathrm{M} \rightarrow \mathrm{ClONO}_{2}+\mathrm{M}$,

and the partitioning of $\mathrm{NO}_{\mathrm{x}}$ is governed, to a good approximation, by the equilibrium between

$\mathrm{O}_{3}+\mathrm{NO} \rightarrow \mathrm{NO}_{2}+\mathrm{O}_{2}$

$\mathrm{ClO}+\mathrm{NO} \rightarrow \mathrm{Cl}+\mathrm{NO}_{2}$

$\mathrm{NO}_{2}+h v \rightarrow \mathrm{NO}+\mathrm{O}$

By using the equilibrium conditions $\mathrm{d}[\mathrm{NO}] / \mathrm{d} t=0$ and $\mathrm{d}\left[\mathrm{ClONO}_{2}\right] / \mathrm{d} t=0$, the product of $\mathrm{ClO}$ and $\mathrm{NO}$ can be expressed by

$[\mathrm{ClO}][\mathrm{NO}]=\frac{\left(k_{\mathrm{R} 10}+k_{\mathrm{R} 11}\right) k_{\mathrm{R} 14}\left[\mathrm{ClONO}_{2}\right]}{k_{\mathrm{R} 12}\left(k_{\mathrm{R} 13}\left[\mathrm{O}_{3}\right]+k_{\mathrm{R} 8}[\mathrm{ClO}]\right)}$.
Unfortunately, the vortex mean of this function can again not be replaced by this function formulated in terms of the vortex means $\left\langle\left[\mathrm{ClONO}_{2}\right]\right\rangle,\left\langle\left[\mathrm{O}_{3}\right]\right\rangle$ and $\left\langle\left[\mathrm{ClO}_{\mathrm{x}}\right]\right\rangle$.

That is, a formulation of term $C_{2}$, which is quantitatively correct and only depends on the vortex means of the variables, is not possible. It is only possible to find a parameterization that results in a good fit and takes into account some important properties of the above equations.

A very good fit for term $C_{2}$ can be achieved by the parameterization

$C_{2}=c_{2} \cdot\left\langle\left[\mathrm{ClONO}_{2}\right]\right\rangle /\left\langle\left[\mathrm{O}_{3}\right]\right\rangle \cdot \mathrm{FAS}^{3}$.

The three FAS factors take the involved photolysis Reactions (R10)/(R11) and (R14) and the area-weighted average into account. The dependence on $\mathrm{ClONO}_{2}$ in Eq. (14) is considered by multiplying by $\left\langle\left[\mathrm{ClONO}_{2}\right]\right\rangle$. The shift of the equilibrium towards high $\mathrm{Cl}$ values for low $\mathrm{O}_{3}$ values by the $\mathrm{Cl}+\mathrm{O}_{3}$ and $\mathrm{NO}+\mathrm{O}_{3}$ reactions is parameterized by dividing by $\left\langle\left[\mathrm{O}_{3}\right]\right\rangle$.

The sum $C_{1}+C_{2}$ is fitted to the sum of the modeled rates of the two Reactions (R1) and (R2). Reaction (R2) is a less important reaction that also depends on $\mathrm{Cl}$. Figure 2 shows the sum of the reaction rates modeled by ATLAS (blue), the fitted term $C=C_{1}+C_{2}$ (red) and the two components $C_{1}$ (orange) and $C_{2}$ (brown) at the second fitted pressure level $(54 \mathrm{hPa})$. The fitted coefficients can be found in Table 3.

\subsubsection{Term $F$}

Term $F$ represents the effect of the reaction of $\mathrm{ClO}$ with $\mathrm{OH}$

$\mathrm{ClO}+\mathrm{OH} \rightarrow \mathrm{HCl}+\mathrm{O}_{2}$,

which helps $\mathrm{HCl}$ formation in both hemispheres. The reaction starts to become important only in late winter, when sunlight comes back and $\mathrm{OH}$ and $\mathrm{ClO}$ are produced in photolytic reaction cycles. Since $\mathrm{ClO}_{\mathrm{x}}$ levels decrease in spring, it is only important for a relatively short period (February to 


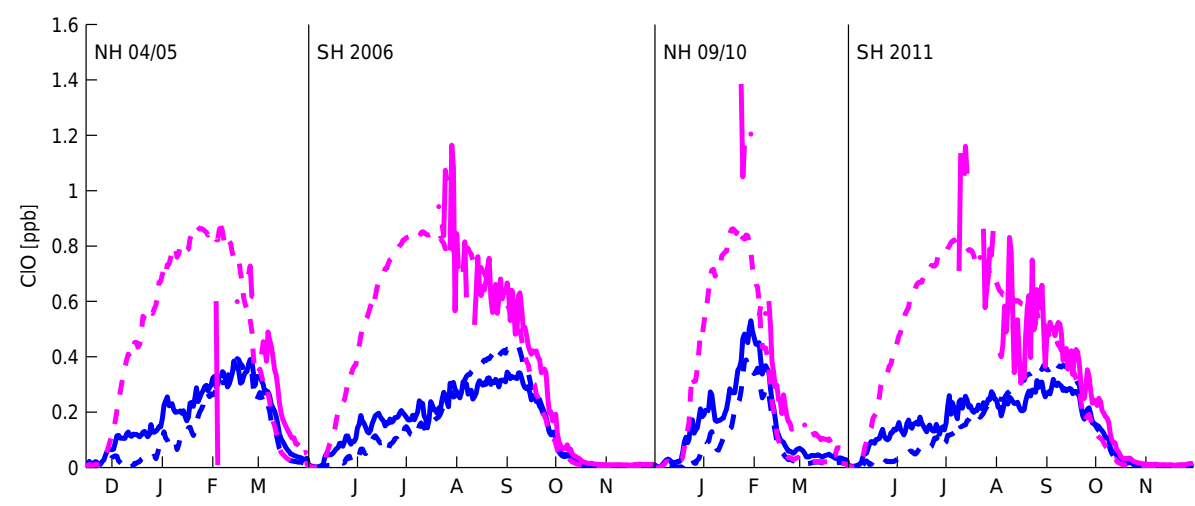

Figure 3. Vortex-averaged mixing ratio of $\mathrm{ClO}$ for the Arctic winter 2004/2005, the Antarctic winter 2006, the Arctic winter 2009/2010 and the Antarctic winter 011 at $54 \mathrm{hPa}$. Vortex average (solid blue) and parameterization for the mixing ratio by $\langle[\mathrm{ClO} \times \mathrm{x}] \cdot \mathrm{FAS}(\mathrm{dashed}$ blue) and average over sunlit part of vortex (solid magenta) and parameterization for the mixing ratio by $\left\langle\left[\mathrm{ClO}_{\mathrm{x}}\right]\right\rangle$ (dashed magenta). Tick marks on the horizontal axis show start of months.

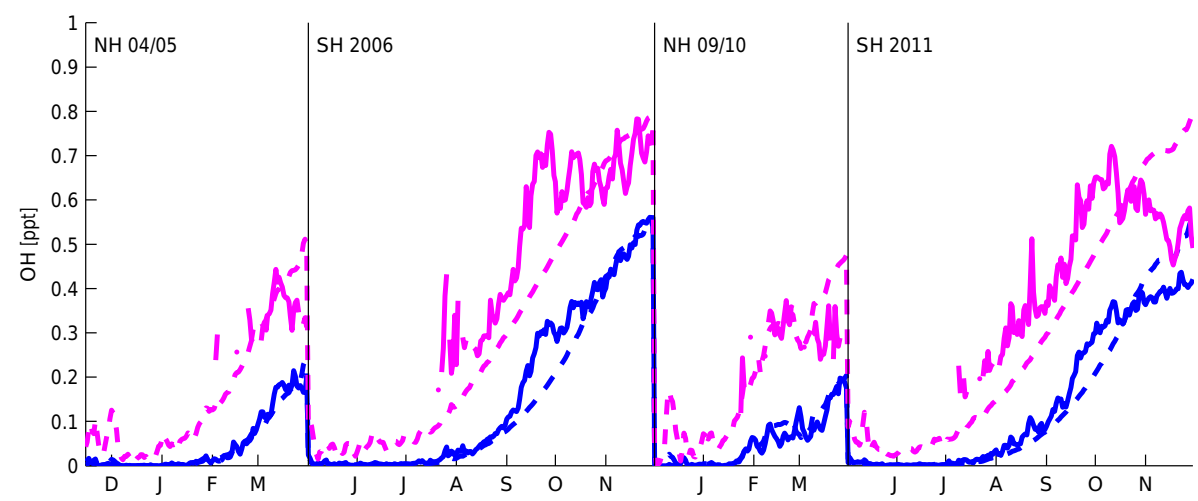

Figure 4. Vortex-averaged mixing ratio of $\mathrm{OH}$ for the Arctic winter 2004/2005, the Antarctic winter 2006, the Arctic winter 2009/2010 and the Antarctic winter 2011 at $54 \mathrm{hPa}$. Vortex average (solid blue) and parameterization for the mixing ratio by FAS ${ }^{2}$ (dashed blue) and average over sunlit part of vortex (solid magenta) and parameterization for the mixing ratio by FAS (dashed magenta). Tick marks on the horizontal axis show start of months.

March in the Northern Hemisphere, September to October in the Southern Hemisphere; Wohltmann et al., 2017). The rate of change of $\mathrm{HCl}$ by this reaction is given by the areaweighted rate of change under sunlit conditions, since there is no $\mathrm{OH}$ and very little $\mathrm{ClO}$ at night

$$
\left\langle\left.\frac{\mathrm{d}[\mathrm{HCl}]}{\mathrm{d} t}\right|_{\mathrm{R} 3}\right\rangle \approx \mathrm{FAS} \cdot\left\langle\left.\frac{\mathrm{d}[\mathrm{HCl}]}{\mathrm{d} t}\right|_{\mathrm{R} 3}\right\rangle_{\mathrm{day}} \text {. }
$$

The rate of change during day can be expressed by

$$
\left\langle\left.\frac{\mathrm{d}[\mathrm{HCl}]}{\mathrm{d} t}\right|_{\mathrm{R} 3}\right\rangle_{\mathrm{day}}=\left\langle k_{\mathrm{R} 3}[\mathrm{ClO}][\mathrm{OH}]\right\rangle_{\mathrm{day}} \text {. }
$$

Contrary to the situation in the last section, the vortex average and the multiplication can be interchanged, to a good approximation, for $\mathrm{ClO}$ and $\mathrm{OH}$

$$
\langle[\mathrm{ClO}][\mathrm{OH}]\rangle_{\text {day }} \approx\langle[\mathrm{ClO}]\rangle_{\text {day }}\langle[\mathrm{OH}]\rangle_{\text {day }} \text {. }
$$

Hence, term $F$ is parameterized by

$$
F=f \cdot\langle[\mathrm{ClO}]\rangle_{\text {day }} \cdot\langle[\mathrm{OH}]\rangle_{\text {day }} \cdot \mathrm{FAS}
$$

with the FAS factor from the area weighting. The mixing ratio $\langle[\mathrm{ClO}]\rangle_{\text {day }}$ is modeled by assuming proportionality to $\mathrm{ClO}_{\mathrm{x}}$

$$
\langle[\mathrm{ClO}]\rangle_{\text {day }} \sim\left\langle\left[\mathrm{ClO}_{\mathrm{x}}\right]\right\rangle
$$

since a relatively constant fraction of $\mathrm{ClO}_{\mathrm{x}}$ is present as $\mathrm{ClO}$ during day. Figure 3 shows that this assumption works well. The mixing ratio $\langle[\mathrm{OH}]\rangle_{\text {day }}$ is modeled by assuming

$$
\langle[\mathrm{OH}]\rangle_{\text {day }} \sim \text { FAS. }
$$

Figure 4 shows that this is a sufficiently good assumption, partly due to the fact that the mixing ratios of $\mathrm{OH}$ are relatively similar in the Northern and Southern hemispheres. In conditions not disturbed by heterogenous chemistry on PSCs, it can be shown that the stratospheric $\mathrm{OH}$ abundance is in relatively good approximation a linear function of the solar zenith angle, mostly independent from the concentrations of other species (Hanisco et al., 2001). In addition, the average solar zenith angle in the vortex is in good approximation 
a linear function of FAS. However, this is not true anymore under conditions of heterogeneous chemistry, and significant deviations from this behavior occur, especially in the Southern Hemisphere (see Fig. 11 in Wohltmann et al., 2017; the effect is also visible in Fig. 4).

Production and loss processes of $\mathrm{HO}_{\mathrm{x}}=\mathrm{OH}+\mathrm{HO}_{2}$ are fairly complicated (Hanisco, 2003; Wohltmann et al., 2017). In particular, it is not possible to find a simple equation that relates the mixing ratios of the relevant source gases $\mathrm{CH}_{4}$, $\mathrm{HNO}_{3}$ and $\mathrm{H}_{2} \mathrm{O}$ to the mixing ratio of $\mathrm{HO}_{\mathrm{x}}$. In addition, the partitioning inside $\mathrm{HO}_{\mathrm{x}}$ depends in a complicated way on $\mathrm{O}_{3}, \mathrm{ClO}_{\mathrm{x}}$ and $\mathrm{NO}_{\mathrm{x}}$ and there are considerable differences in the partitioning of $\mathrm{HO}_{\mathrm{x}}$ between $\mathrm{OH}$ and $\mathrm{HO}_{2}$ in the Northern and Southern hemispheres (see Wohltmann et al., 2017). Hence, only an empirical parameterization that is not a function of the source gases is given here. Note that this means that the Polar SWIFT model implicitly uses the water vapor and methane levels of the ATLAS model runs and that it is not possible to model responses to changes in these source gases with Polar SWIFT.

Term $F$ is fitted to the modeled rate of Reaction (R3). Figure 5 shows the modeled reaction rate and the fitted term $F$.

\subsubsection{Term $A$}

Term $A$ accounts for the effect of the most important heterogeneous reaction activating chlorine

$\mathrm{HCl}+\mathrm{ClONO}_{2} \rightarrow \mathrm{Cl}_{2}+\mathrm{HNO}_{3}$.

The parameterization of term $A$ remains similar to the parameterization in the original model. For high $\mathrm{HCl}$, it is given by

$A=a \cdot\left\langle\left[\mathrm{ClONO}_{2}\right]\right\rangle \cdot\left\langle\left[\mathrm{HNO}_{3}\right]\right\rangle^{2 / 3} \cdot \mathrm{FAP}$

and for low $\mathrm{HCl}$ it is given by

$A=a \cdot\langle[\mathrm{HCl}]\rangle \cdot\left\langle\left[\mathrm{ClONO}_{2}\right]\right\rangle \cdot\left\langle\left[\mathrm{HNO}_{3}\right]\right\rangle^{2 / 3} \cdot \mathrm{FAP}$.

The threshold for $\mathrm{HCl}$ is set to $1 \mathrm{ppt}$. Reaction rates for heterogeneous reactions are proportional to the surface area density of the liquid or solid particles in the ATLAS model. The surface area density is modeled by $\left\langle\left[\mathrm{HNO}_{3}\right]\right\rangle^{2 / 3}$. FAP. Here, we assume that cloud particles are mainly composed of $\mathrm{HNO}_{3}$, that all $\mathrm{HNO}_{3}$ is in liquid or solid form in the area below the threshold temperature used for FAP and that all $\mathrm{HNO}_{3}$ outside this area is in the gas phase. In the original model, the parameterization $\left\langle\left[\mathrm{HNO}_{3}\right]\right\rangle \cdot \mathrm{FAP}$ was used. In the new model, $\left\langle\left[\mathrm{HNO}_{3}\right]\right\rangle$ is raised to the power of $2 / 3$ to account for the difference between particle volume density (proportional to the mixing ratio of liquid or solid $\mathrm{HNO}_{3}$ per volume of air) and particle surface area density (surface is proportional to volume raised to the power of $2 / 3$ ).

For heterogeneous reactions on NAT, reaction rates are not proportional to $\mathrm{HCl}$; i.e., the change of $\mathrm{HCl}$ is given by

$$
\left.\frac{\mathrm{d}[\mathrm{HCl}]}{\mathrm{d} t}\right|_{\mathrm{R} 4}=-k_{\mathrm{R} 4}\left[\mathrm{ClONO}_{2}\right] \text {, }
$$

where $k_{\mathrm{R} 4}$ is a pseudo first-order rate coefficient, which is not a function of $\mathrm{HCl}$. This is not the case for reactions on liquid STS surfaces, where the rate depends on the concentration of $\mathrm{HCl}$ (Fig. 6). Activation mainly occurs on liquid surfaces in the model runs. The sensitivity of the reaction rate on the $\mathrm{HCl}$ concentration is nonlinear, with a rapid increase between 0 and $0.3 \mathrm{ppb}$. The reaction rate becomes relatively independent of $\mathrm{HCl}$ above $0.3 \mathrm{ppb}$. Hence, a parameterization that does not depend on $\mathrm{HCl}$ is a good approximation and gives a better fit than a parameterization that depends linearly on $\mathrm{HCl}$.

Term $A$ is fitted to the modeled rate of the heterogeneous Reaction (R4). Figure 7 shows the modeled rate of this reaction (blue) and the fitted term $A$ (red).

\subsubsection{Term $L$}

The new term $L$ accounts for the effect of the heterogeneous reaction

$\mathrm{HOCl}+\mathrm{HCl} \rightarrow \mathrm{Cl}_{2}+\mathrm{H}_{2} \mathrm{O}$,

which can activate a significant part of chlorine in the Southern Hemisphere and a non-negligible part in the Northern Hemisphere. In the original model, this contribution was implicitly subsumed into term $A$. However, since we use term $A$ both in the $\mathrm{HCl}$ equation and in the $\mathrm{ClONO}_{2}$ equation with the same fit parameter $a$, we introduce an additional term here to represent the $\mathrm{HCl}$ loss by $\mathrm{HOCl}+\mathrm{HCl}$. Similar to the approach for term $A$, term $L$ is parameterized by

$L=l \cdot\langle[\mathrm{HOCl}]\rangle \cdot\langle[\mathrm{HCl}]\rangle \cdot\left\langle\left[\mathrm{HNO}_{3}\right]\right\rangle^{2 / 3} \cdot$ FAP.

$\mathrm{HOCl}$ is parameterized by

$\langle[\mathrm{HOCl}]\rangle \sim\langle[\mathrm{ClO}]\rangle_{\text {day }} \cdot$ FAS.

$\mathrm{HOCl}$ is in a fast equilibrium between

$\mathrm{ClO}+\mathrm{HO}_{2} \rightarrow \mathrm{HOCl}+\mathrm{O}_{2}$

and

$\mathrm{HOCl}+h v \rightarrow \mathrm{Cl}+\mathrm{OH}$

under sunlit conditions. Using the equilibrium condition, we obtain

$\langle[\mathrm{HOCl}]\rangle_{\text {day }}=\left\langle\frac{k_{\mathrm{R} 15}}{k_{\mathrm{R} 16}}[\mathrm{ClO}]\left[\mathrm{HO}_{2}\right]\right\rangle_{\text {day }}$.

Now, we assume that the ratio of $\left[\mathrm{HO}_{2}\right]$ and $k_{\mathrm{R} 16}$ is nearly constant, since both terms depend on the amount of sunlight, which gives

$\langle[\mathrm{HOCl}]\rangle_{\text {day }} \sim\langle[\mathrm{ClO}]\rangle_{\text {day }}$.

$\langle[\mathrm{ClO}]\rangle_{\text {day }}$ is parameterized by $\left\langle\left[\mathrm{ClO}_{\mathrm{x}}\right]\right\rangle$ (see discussion of term $F$ and Fig. 3). If we assume that there is no $\mathrm{HOCl}$ during night, we obtain

$\langle[\mathrm{HOCl}]\rangle=\langle[\mathrm{HOCl}]\rangle_{\text {day }} \cdot$ FAS. 


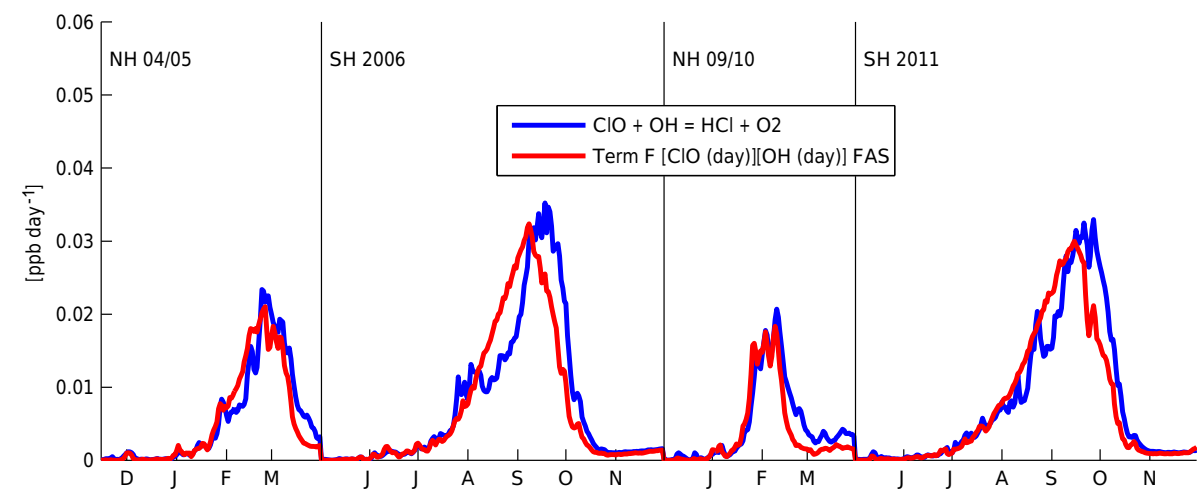

Figure 5. Fit of term $F$ for the Arctic winter 2004/2005, the Antarctic winter 2006, the Arctic winter 2009/2010 and the Antarctic winter 2011 at $54 \mathrm{hPa}$. Vortex-averaged reaction rate modeled by ATLAS for the reaction $\mathrm{ClO}+\mathrm{OH}$ (blue) and the fitted term $F$ (red). Tick marks on the horizontal axis show start of months.

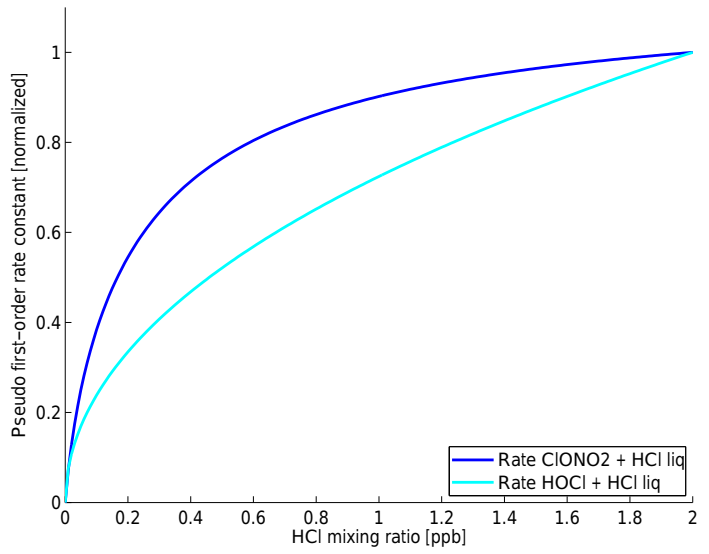

Figure 6. Normalized pseudo first-order rate coefficients as a function of $\mathrm{HCl}$ mixing ratio for the heterogeneous reactions $\mathrm{ClONO}_{2}+\mathrm{HCl}$ (blue) and $\mathrm{HOCl}+\mathrm{HCl}$ (cyan) on liquid STS surfaces. Reaction rates were calculated for $T=190 \mathrm{~K}, p=50 \mathrm{hPa}$, $10 \mathrm{ppb} \mathrm{HNO}_{3}, 0.15$ ppb $\mathrm{H}_{2} \mathrm{SO}_{4}, 4$ ppm $\mathrm{H}_{2} \mathrm{O}$ and 1 ppb $\mathrm{ClONO}_{2}$.

This assumption is not straightforward. If the heterogenous reaction $\mathrm{HOCl}+\mathrm{HCl}$ did not take place, night-time mixing ratios of $\mathrm{HOCl}$ would remain at mixing ratios similar to the daytime values, since the Reactions (R15) and (R16) do not proceed during night. However, the parameterization for term $L$ is only different from zero when heterogenous reactions can proceed (due to the FAP term) and when enough chlorine is activated (due to the $\left\langle\left[\mathrm{ClO}_{\mathrm{x}}\right]\right\rangle$ term). Under these conditions, $\mathrm{HOCl}$ is depleted by the $\mathrm{HOCl}+\mathrm{HCl}$ reaction during night.

$\mathrm{HOCl}+\mathrm{HCl}$ is a heterogeneous reaction, whose reaction rate will be proportional to FAP. The rate of the $\mathrm{HOCl}+\mathrm{HCl}$ reaction shows a more linear dependency on $\mathrm{HCl}$ mixing ratios than the $\mathrm{ClONO}_{2}+\mathrm{HCl}$ reaction (Fig. 6). Hence, we include the $\mathrm{HCl}$ mixing ratio as a linear factor in term $L$, which improves the fit compared to a parameterization that does not depend on $\mathrm{HCl}$. Still, term $L$ shows one of the poorer fits compared to the other parameterizations.

Term $L$ is fitted to the modeled reaction rate of the heterogeneous Reaction (R5). Figure 8 shows the modeled reaction rate of this reaction and the fitted term $L$.

\subsubsection{Term $K$}

A reaction not included in the original model that affects the redistribution of $\mathrm{HCl}$ and $\mathrm{ClONO}_{2}$ in late winter and spring is

$\mathrm{HCl}+\mathrm{OH} \rightarrow \mathrm{H}_{2} \mathrm{O}+\mathrm{Cl}$

as shown in Wohltmann et al. (2017). In spring, this reaction consumes much of the $\mathrm{HCl}$ that is produced by $\mathrm{Cl}+\mathrm{CH}_{4}$. The reaction is represented by a new term $K$, which is parameterized by

$K=k \cdot\langle[\mathrm{HCl}]\rangle \cdot\langle[\mathrm{OH}]\rangle_{\text {day }} \cdot \mathrm{FAS}$.

The equation is derived analogously to the equation for term $F$. We multiply by FAS again to take the average over the sunlit area into account. Term $K$ is fitted to the modeled rate of Reaction (R6). Figure 9 shows the modeled reaction rate and the fitted term $K$.

\section{$3.2 \mathrm{ClONO}_{2}$}

\subsubsection{Overview}

The equation for $\mathrm{ClONO}_{2}$ is changed from

$\frac{\mathrm{d}\left\langle\left[\mathrm{ClONO}_{2}\right]\right\rangle}{\mathrm{d} t}=B-A-G-H$

in the original model to

$\frac{\mathrm{d}\left\langle\left[\mathrm{ClONO}_{2}\right]\right\rangle}{\mathrm{d} t}=B-A-H$ 


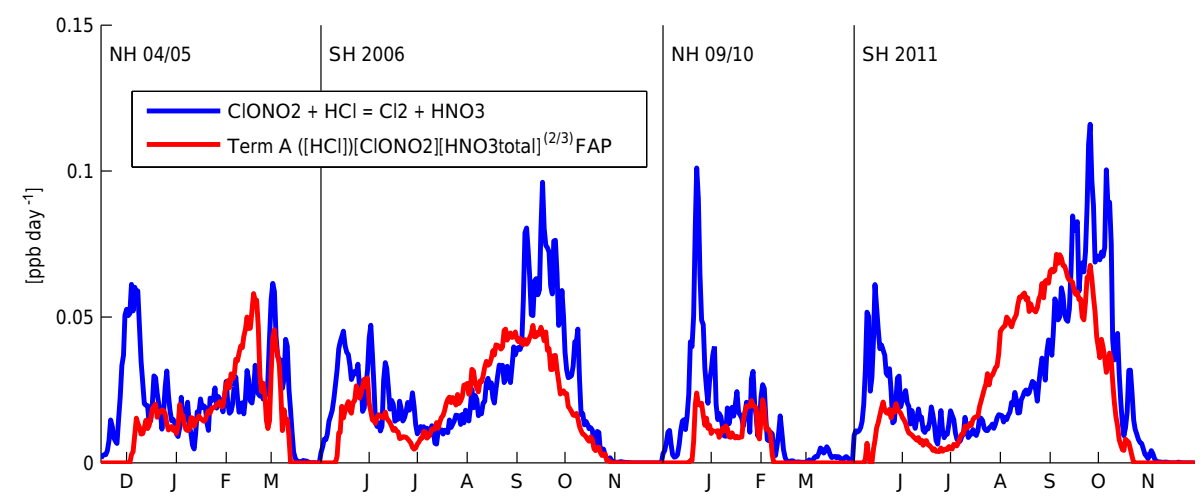

Figure 7. Fit of term $A$ for the Arctic winter 2004/2005, the Antarctic winter 2006, the Arctic winter 2009/2010 and the Antarctic winter 2011 at $54 \mathrm{hPa}$. Vortex-averaged reaction rate modeled by ATLAS for the reaction $\mathrm{HCl}+\mathrm{ClONO}_{2}$ (blue) and the fitted term $A$ (red). Tick marks on the horizontal axis show start of months.

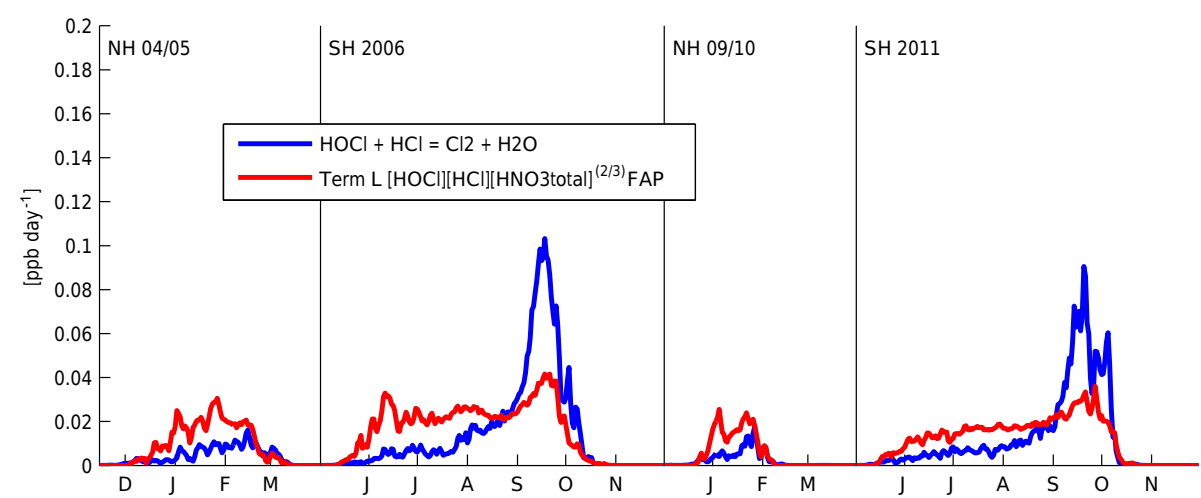

Figure 8. Fit of term $L$ for the Arctic winter 2004/2005, the Antarctic winter 2006, the Arctic winter 2009/2010 and the Antarctic winter 2011 at $54 \mathrm{hPa}$. Vortex-averaged reaction rate modeled by ATLAS for the reaction $\mathrm{HOCl}+H \mathrm{Cl}$ (blue) and the fitted term $L$ (red). Tick marks on the horizontal axis show start of months.

in the new model. $\mathrm{ClONO}_{2}$ is in a near equilibrium between

$$
\begin{aligned}
\mathrm{ClONO}_{2}+h v & \rightarrow \mathrm{Cl}+\mathrm{NO}_{3} \\
& \rightarrow \mathrm{ClO}+\mathrm{NO}_{2}
\end{aligned}
$$

and

$$
\mathrm{ClO}+\mathrm{NO}_{2}+\mathrm{M} \rightarrow \mathrm{ClONO}_{2}+\mathrm{M} .
$$

In the new model version, the net effect of these reactions (and of some additional $\mathrm{ClONO}_{2}$ loss reactions) is described by term $B$, while in the original model, there were two different additive terms $B$ and $G$. The net change of $\mathrm{ClONO}_{2}$ by the above reactions is responsible for deactivation of active chlorine in the Northern Hemisphere. Term $A$ accounts again for the effect of the heterogeneous reaction

$$
\mathrm{HCl}+\mathrm{ClONO}_{2} \rightarrow \mathrm{Cl}_{2}+\mathrm{HNO}_{3},
$$

which both activates $\mathrm{HCl}$ and $\mathrm{ClONO}_{2}$, while term $H$ accounts for the effect of the less important heterogeneous reaction

$\mathrm{ClONO}_{2}+\mathrm{H}_{2} \mathrm{O} \rightarrow \mathrm{HOCl}+\mathrm{HNO}_{3}$ which only activates $\mathrm{ClONO}_{2}$.

\subsubsection{Term $B$}

Term $B$ represents the net effect of the Reactions (R10)/(R11) and (R12). $\mathrm{ClONO}_{2}$ is in an equilibrium between Reactions (R10)/(R11) and (R12) (Wohltmann et al., 2017). Changes in $\mathrm{ClONO}_{2}$ by a shift in this equilibrium are mainly induced by the production of $\mathrm{NO}_{\mathrm{x}}$ $\left(\mathrm{NO}_{\mathrm{x}}=\mathrm{NO}+\mathrm{NO}_{2}+\mathrm{NO}_{3}+2 \mathrm{~N}_{2} \mathrm{O}_{5}\right)$. Since $\mathrm{NO}_{\mathrm{x}}$ is mainly produced by the comparably slow reactions

$$
\begin{aligned}
& \mathrm{HNO}_{3}+h v \rightarrow \mathrm{NO}_{2}+\mathrm{OH} \\
& \mathrm{HNO}_{3}+\mathrm{OH} \rightarrow \mathrm{H}_{2} \mathrm{O}+\mathrm{NO}_{3}
\end{aligned}
$$

these reactions determine the net production of $\mathrm{ClONO}_{2}$. The equilibrium condition for $\mathrm{ClONO}_{2}$ can be written as

$\left[\mathrm{ClONO}_{2}\right] \sim[\mathrm{ClO}]\left[\mathrm{NO}_{2}\right]$.

Production of $\mathrm{NO}_{\mathrm{x}}$ will increase $\mathrm{NO}_{2}$. In turn, $\mathrm{ClONO}_{2}$ will increase almost instantly at the expense of $\mathrm{NO}_{2}$ to match the 


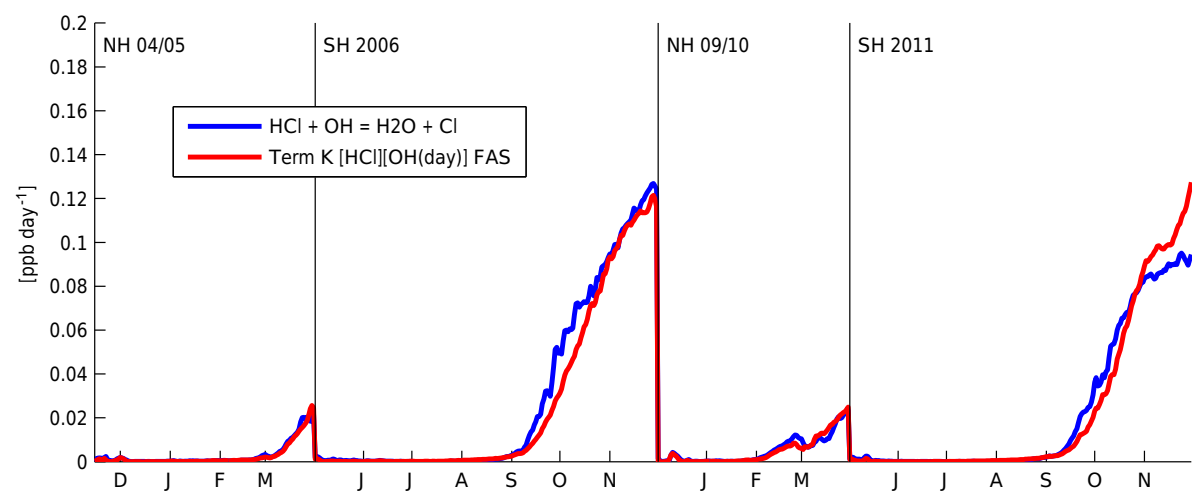

Figure 9. Fit of term $K$ for the Arctic winter 2004/2005, the Antarctic winter 2006, the Arctic winter 2009/2010 and the Antarctic winter 2011 at $54 \mathrm{hPa}$. Vortex-averaged reaction rate modeled by ATLAS for the reaction $\mathrm{HCl}+\mathrm{OH}$ (blue) and the fitted term $K$ (red). Tick marks on the horizontal axis show start of months.

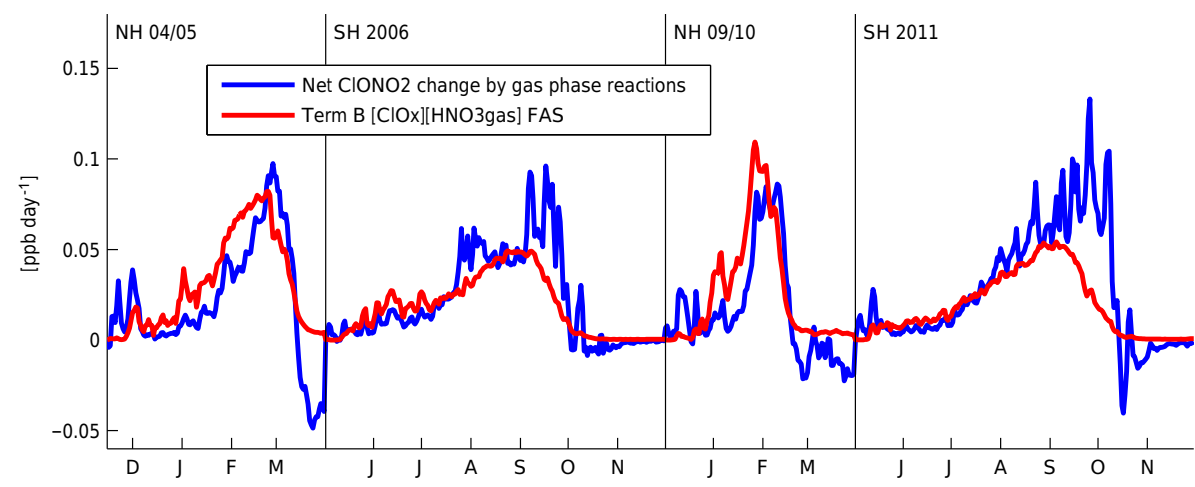

Figure 10. Fit of term $B$ for the Arctic winter 2004/2005, the Antarctic winter 2006, the Arctic winter 2009/2010 and the Antarctic winter 2011 at $54 \mathrm{hPa}$. Sum of the vortex-averaged reaction rates modeled by ATLAS for the reactions $\mathrm{ClONO}_{2}+h v$ (both channels), $\mathrm{ClO}+\mathrm{NO}_{2}, \mathrm{ClONO}_{2}+\mathrm{Cl}, \mathrm{ClONO}_{2}+\mathrm{OH}$ and $\mathrm{ClONO}_{2}+\mathrm{O}$ (blue) and the fitted term $B$ (red). Tick marks on the horizontal axis show start of months.

equilibrium condition again. In this sense, $\mathrm{ClONO}_{2}$ can be considered a part of $\mathrm{NO}_{\mathrm{x}}$, which is mainly partitioned into $\mathrm{NO}, \mathrm{NO}_{2}$ and $\mathrm{ClONO}_{2}$. Term $B$ is parameterized by

$B=b \cdot\left\langle\left[\mathrm{ClO}_{\mathrm{x}}\right]\right\rangle \cdot\left\langle\left[\mathrm{HNO}_{3}\right]_{\mathrm{g}}\right\rangle \cdot \mathrm{FAS}$,

where $\left[\mathrm{HNO}_{3}\right]_{\mathrm{g}}$ denotes $\mathrm{HNO}_{3}$ in the gas phase. This parameterization is obtained empirically, since it is again difficult to derive an expression from the chemical equations, and qualitatively takes into account the properties of the $\mathrm{ClONO}_{2}$ equilibrium. The change of $\mathrm{NO}_{\mathrm{x}}$ is parameterized empirically as $\left\langle\left[\mathrm{HNO}_{3}\right]_{\mathrm{g}}\right\rangle \cdot$ FAS taking into account that $\mathrm{NO}_{\mathrm{x}}$ is produced from $\mathrm{HNO}_{3}$ under sunlit conditions. Term $B$ is fitted to the sum of the modeled rates of the following reactions

$$
\begin{aligned}
& \mathrm{ClO}+\mathrm{NO}_{2}+\mathrm{M} \rightarrow \mathrm{ClONO}_{2}+\mathrm{M} \\
& \mathrm{ClONO}_{2}+h v \rightarrow \mathrm{Cl}+\mathrm{NO}_{3} \\
& \mathrm{ClONO}_{2}+h v \rightarrow \mathrm{ClO}+\mathrm{NO}_{2} \\
& \mathrm{ClONO}_{2}+\mathrm{Cl} \rightarrow \mathrm{Cl}_{2}+\mathrm{NO}_{3} \\
& \mathrm{ClONO}_{2}+\mathrm{OH} \rightarrow \mathrm{HOCl}+\mathrm{NO}_{3}
\end{aligned}
$$

$$
\mathrm{ClONO}_{2}+\mathrm{O} \rightarrow \mathrm{ClO}+\mathrm{NO}_{3}
$$

The main channel of the photolysis reaction is into $\mathrm{Cl}+\mathrm{NO}_{3}$ (Reaction R10), but the minor channel Reaction (R11) into $\mathrm{ClO}+\mathrm{NO}_{2}$ is also included in the fit. In addition, we include several reactions of the form $\mathrm{ClONO}_{2}+X$ in the fit, where $X$ is one of $\mathrm{Cl}, \mathrm{OH}$ or $\mathrm{O}$. Figure 10 shows the sum of the modeled reaction rates for these reactions and the fitted term $B$.

\subsubsection{Term $A$}

See explanation in Sect. 3.1.4.

\subsubsection{Term $\boldsymbol{H}$}

Term $H$ accounts for the effect of the heterogeneous reaction

$$
\mathrm{ClONO}_{2}+\mathrm{H}_{2} \mathrm{O} \rightarrow \mathrm{HOCl}+\mathrm{HNO}_{3} .
$$

Term $H$ is parameterized by

$$
H=h \cdot\left\langle\left[\mathrm{ClONO}_{2}\right]\right\rangle \cdot\left\langle\left[\mathrm{HNO}_{3}\right]\right\rangle^{2 / 3} \cdot \mathrm{FAP}
$$


in the new model. The parameterization for term $H$ remains similar to the original model. The term $\max (\mathrm{FAP}-y, 0)$ of the original model (with $y$ a fitted parameter) is exchanged by $\left\langle\left[\mathrm{HNO}_{3}\right]\right\rangle^{2 / 3}$. FAP.

$h$ is fitted to the modeled rate of Reaction (R17). The fit has a rather large residuum both with the original and the new parameterization. This is relativized by the fact that the $\mathrm{ClONO}_{2}+\mathrm{H}_{2} \mathrm{O}$ reaction is only of minor importance for chlorine activation and $\mathrm{ClONO}_{2}$ removal. One of the reasons for the disagreement may be the complicated dependence of the $\gamma$ value of the reaction on $\mathrm{H}_{2} \mathrm{O}$ (see Fig. 11). Figure 12 shows the modeled reaction rate and the fitted term $H$.

\section{$3.3 \mathrm{HNO}_{3}$}

The change in the total amount of $\mathrm{HNO}_{3}$ (i.e., the sum of the gas phase and the condensed phase) is given by

$\frac{\mathrm{d}\left\langle\left[\mathrm{HNO}_{3}\right]\right\rangle}{\mathrm{d} t}=-E$

both in the original and in the new model. Changes in $\mathrm{HNO}_{3}$ are dominated by changes due to denitrification, i.e., the irreversible removal of $\mathrm{HNO}_{3}$ by sedimenting cloud particles. Term $E$ is parameterized by

$E=e \cdot\left\langle\left[\mathrm{HNO}_{3}\right]\right\rangle \cdot \mathrm{FAP}_{\mathrm{s}}$.

The term $\max (\mathrm{FAP}-y, 0)$ of the original model is replaced by FAP $_{\mathrm{s}}$ in the new model. The rate of change by sedimenting particles is assumed to be proportional to the volume of $\mathrm{HNO}_{3}$ condensed in the cloud particles. For this, it is assumed that the amount of $\mathrm{HNO}_{3}$ that is in the cloud particles is proportional to the total amount of $\mathrm{HNO}_{3}$ inside the area indicated by $\mathrm{FAP}_{\mathrm{s}}$ and that the $\mathrm{HNO}_{3}$ mixing ratio is proportional to the particle volume. Additionally, it is assumed that there are no cloud particles outside the area indicated by $\mathrm{FAP}_{\mathrm{S}}$. $\mathrm{FAP}_{\mathrm{S}}$ is chosen because denitrification is modeled by sedimenting large NAT particles, which form above a given supersaturation.

$e$ is fitted to the modeled change by sedimenting particles plus the modeled sum of all reactions changing $\mathrm{HNO}_{3}$ (which is small). Figure 13 shows the modeled rate of change of $\mathrm{HNO}_{3}$ and the fitted term $E$.

The partitioning between $\mathrm{HNO}_{3}$ in the gas phase and in the liquid and solid phase is calculated by

$$
\begin{aligned}
\left\langle\left[\mathrm{HNO}_{3}\right]_{\mathrm{g}}\right\rangle & =\left(1-\mathrm{FAP}_{\mathrm{s}}\right) \cdot\left\langle\left[\mathrm{HNO}_{3}\right]\right\rangle+z \cdot \mathrm{FAP}_{\mathrm{s}} \\
\cdot & \left\langle\left[\mathrm{HNO}_{3}\right]\right\rangle
\end{aligned}
$$

in the new version. In the original version, FAP was used for FAP $_{\mathrm{s}} . z$ is obtained by a simple linear fit from Eq. (38) and the model results for $\mathrm{FAP}_{\mathrm{s}}$, $\left[\mathrm{HNO}_{3}\right]$ and $\left[\mathrm{HNO}_{3}\right]_{\mathrm{g}}$.

\section{$\begin{array}{ll}3.4 & \mathrm{O}_{3}\end{array}$}

The rate of change of ozone is given by

$$
\frac{\mathrm{d}\left\langle\left[\mathrm{O}_{3}\right]\right\rangle}{\mathrm{d} t}=-D,
$$

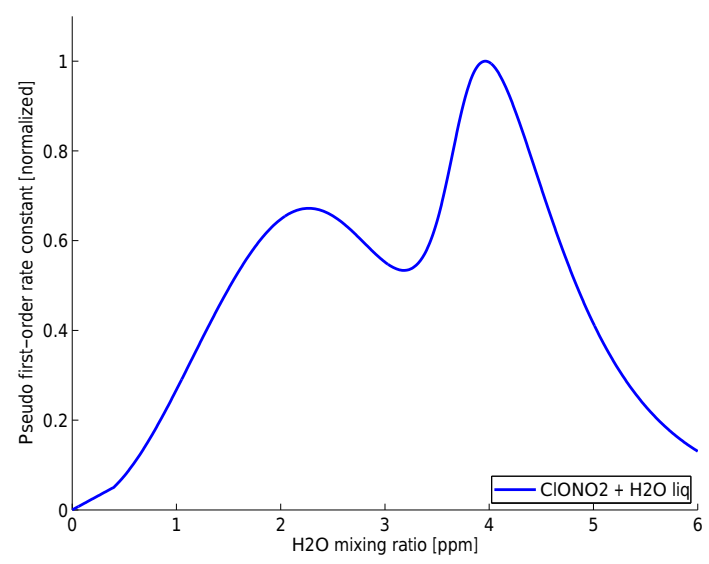

Figure 11. Normalized pseudo first-order rate coefficient of $\mathrm{ClONO}_{2}$ loss as a function of $\mathrm{H}_{2} \mathrm{O}$ mixing ratio for the heterogeneous reaction $\mathrm{ClONO}_{2}+\mathrm{H}_{2} \mathrm{O}$ on liquid STS surfaces. Reaction rates were calculated for $T=190 \mathrm{~K}, p=50 \mathrm{hPa}, 10 \mathrm{ppb} \mathrm{HNO}_{3}$, $0.15 \mathrm{ppb} \mathrm{H}_{2} \mathrm{SO}_{4}, 2 \mathrm{ppb} \mathrm{HCl}$ and 1 ppb $\mathrm{ClONO}_{2}$.

where term $D$ is parameterized by

$D=d \cdot\left\langle\left[\mathrm{ClO}_{\mathrm{x}}\right]\right\rangle \cdot \mathrm{FAS}$.

Term $D$ remains unchanged compared to the original model. The parameterization is based on the fact that the combined effect of the most important catalytic ozone destruction cycles (the $\mathrm{ClO}$ dimer cycle and $\mathrm{ClO}-\mathrm{BrO}$ cycle) is a nearly linear dependence of ozone destruction on $\mathrm{ClO}_{\mathrm{x}}$ (Rex et al., 2014). In addition, the rate of change of ozone depends on the amount of available sunlight due to the $\mathrm{ClO}$ dimer photolysis reaction.

The $\mathrm{ClO}$ dimer cycle alone would lead to a quadratic dependence on $\mathrm{ClO}$ in the sunlit part of the vortex, since the reaction

$\mathrm{ClO}+\mathrm{ClO}+\mathrm{M} \rightarrow \mathrm{Cl}_{2} \mathrm{O}_{2}+\mathrm{M}$

is the rate-limiting step in the cycle. That would lead to the parameterization $\left\langle\left[\mathrm{ClO}_{\mathrm{x}}\right]\right\rangle^{2} \mathrm{FAS}$, since $\langle[\mathrm{ClO}]\rangle_{\text {day }} \sim\left\langle\left[\mathrm{ClO}_{\mathrm{x}}\right]\right\rangle$ (see Fig. 3) and $\mathrm{ClO}$ is only present in the sunlit part of the vortex. The nearly linear dependence of the rate of change of ozone on $\mathrm{ClO}_{\mathrm{x}}$ for the sum of the effect of both cycles has several reasons: the dependence of the rate of change of ozone on $\mathrm{ClO}_{\mathrm{x}}$ caused by the $\mathrm{ClO}-\mathrm{BrO}$ cycle, the dependence of the rate of change of ozone on $\mathrm{ClO}_{\mathrm{x}}$ caused by the $\mathrm{ClO}$ dimer cycle, and the repartitioning of $\mathrm{ClO}$ and $\mathrm{BrO}$.

The fact that most of the $\mathrm{ClO}_{\mathrm{x}}$ that is set free from the heterogeneous reactions is in the form of $\mathrm{Cl}_{2}$ in early winter and needs to be photolyzed into $\mathrm{Cl}$ can be ignored for the purpose of our model, since this happens before substantial ozone depletion is observed.

The amount of $\mathrm{Br}_{\mathrm{y}}$ is not explicitly parameterized in the Polar SWIFT model. The effect of $\mathrm{Br}_{\mathrm{y}}$ is implicitly included since the magnitude of the rate of change of ozone depends 


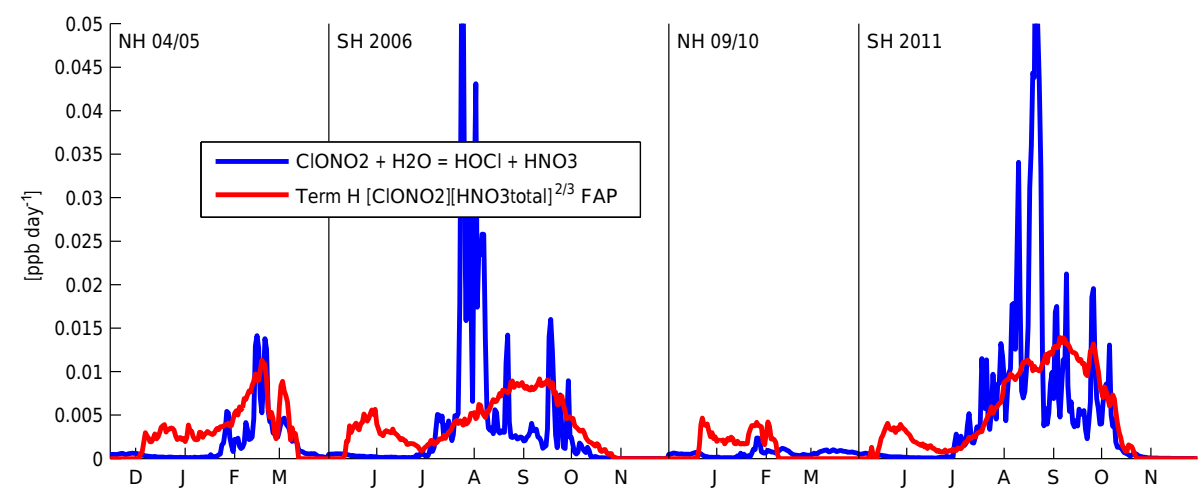

Figure 12. Fit of term $H$ for the Arctic winter 2004/2005, the Antarctic winter 2006, the Arctic winter 2009/2010 and the Antarctic winter 2011 at $54 \mathrm{hPa}$. Vortex-averaged reaction rate modeled by ATLAS for the reaction $\mathrm{ClONO}_{2}+\mathrm{H}_{2} \mathrm{O}$ (blue) and the fitted term $H$ (red). Tick marks on the horizontal axis show start of months.

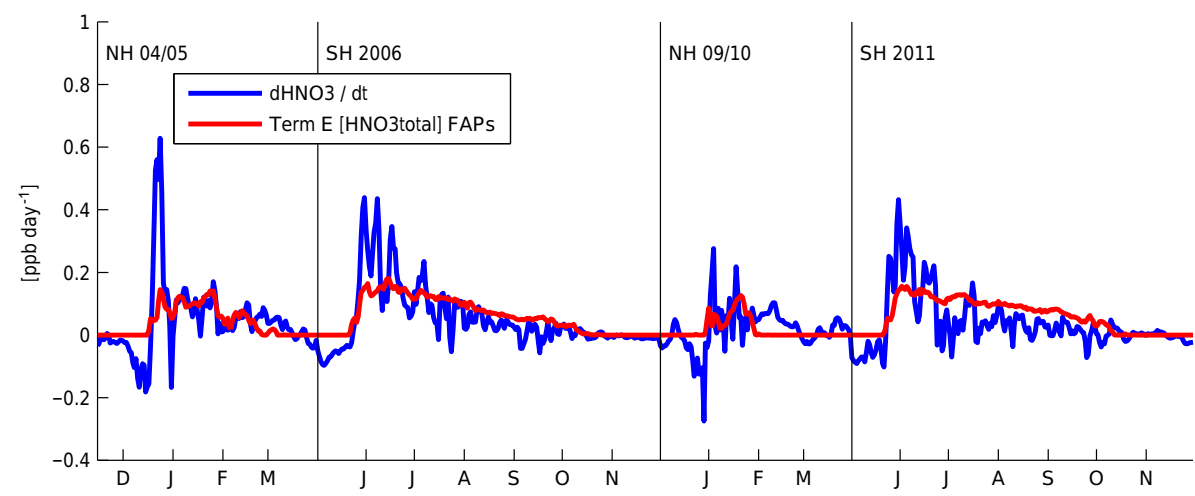

Figure 13. Fit of term $E$ for the Arctic winter 2004/2005, the Antarctic winter 2006, the Arctic winter 2009/2010 and the Antarctic winter 2011 at $54 \mathrm{hPa}$. Vortex-averaged rate of change of $\mathrm{HNO}_{3}$ by denitrification modeled by ATLAS plus the rate of change of $\mathrm{HNO}_{3}$ by chemical reactions modeled by ATLAS (blue) and the fitted term $E$ (red). Tick marks on the horizontal axis show start of months.

on the ClO-BrO cycle. The ATLAS runs that are used for the fits are initialized with a maximum $\mathrm{Br}_{\mathrm{y}}$ of $19.9 \mathrm{ppt}$. Note that this means that the Polar SWIFT model implicitly uses the bromine levels that are given in the ATLAS model runs and that it is not possible to model responses to changes in bromine with Polar SWIFT.

Term $D$ is fitted to the sum of the modeled reaction rates of all reactions changing ozone. Figure 14 shows the modeled reaction rates and the fitted term $D$. The figure shows that the parameterization works very well for ozone.

\section{Validation}

The species mixing ratios simulated by the Polar SWIFT model are compared to corresponding measurements of the MLS satellite instrument and to simulations by the full stratospheric scheme of the ATLAS model for validation. Polar SWIFT is implemented into the ATLAS model for the validation runs and uses the transport and mixing scheme of the ATLAS model, while the detailed stratospheric chemistry scheme of the ATLAS model is replaced by the simplified
Polar SWIFT model. Runs are driven by ECMWF ERA Interim reanalysis data. This approach is needed to obtain results from Polar SWIFT that can be compared to measured data.

Polar SWIFT is implemented in ATLAS by adding the rate of change of ozone calculated by Polar SWIFT for a given layer to the ozone value of every air parcel inside the vortex and inside this layer. Note that this means that the ozone field does still vary across the vortex. The same is done for the other species $\mathrm{HCl}, \mathrm{ClONO}_{2}$ and $\mathrm{HNO}_{3}$. The vortex means of these species, which are needed as input at the start of every time step, are obtained by averaging over all air parcels inside the vortex in the layer. Outside of the polar vortex, $\mathrm{O}_{3}, \mathrm{Cl}_{\mathrm{y}}$, $\mathrm{HCl}, \mathrm{HNO}_{3}$ and $\mathrm{ClONO}_{2}$ are re-initialized every day with seasonal climatologies. For $\mathrm{O}_{3}$ and $\mathrm{HNO}_{3}$, a seasonal climatology based on all available MLS data is used (i.e., which is a function of the month of year, with data from all years averaged). $\mathrm{Cl}_{\mathrm{y}}, \mathrm{ClONO}_{2}$ and $\mathrm{HCl}$ are taken from a seasonal climatology derived from ATLAS runs with the full chemistry model. While $\mathrm{HCl}$ is available from MLS data, it is not 


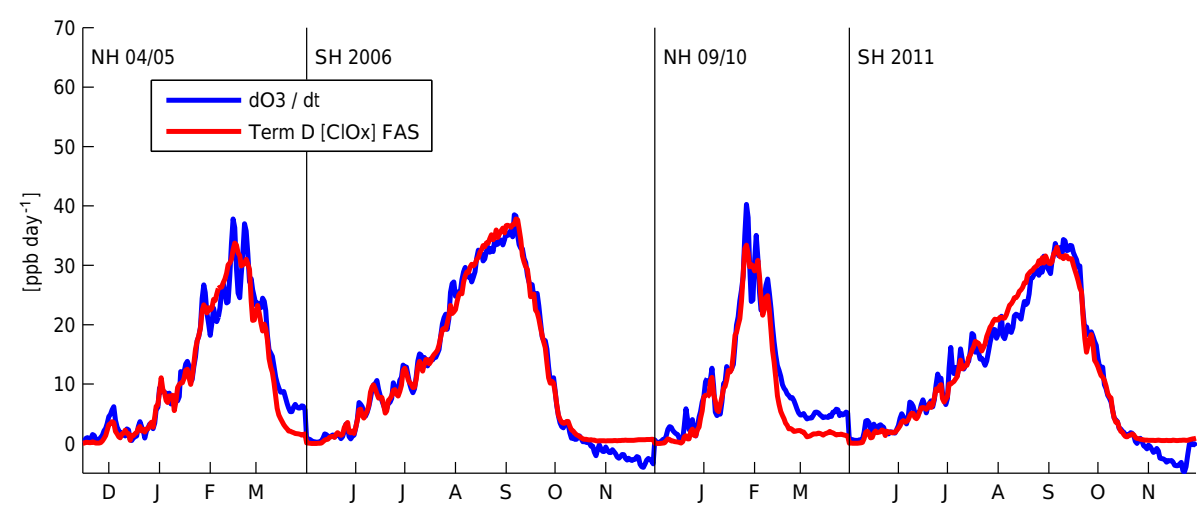

Figure 14. Fit of term $D$ for the Arctic winter 2004/2005, the Antarctic winter 2006, the Arctic winter 2009/2010 and the Antarctic winter 2011 at $54 \mathrm{hPa}$. Vortex-averaged rate of change of $\mathrm{O}_{3}$ by all reactions modeled by ATLAS (blue) and the fitted term $D$ (red). Tick marks on the horizontal axis show start of months.

used here so that the sum of $\mathrm{HCl}$ and $\mathrm{ClONO}_{2}$ is consistent with $\mathrm{Cl}_{\mathrm{y}}$.

Simulations of the Arctic winters 1979/1980-2013/2014 and the Antarctic winters 1980-2014 are conducted. The simulated interannual variability of ozone is compared to the observed interannual variability derived from MLS satellite data for the years 2005 to 2014 .

For every winter and hemisphere, a new run is started, which is initialized with species mixing ratios from the same MLS and ATLAS climatologies that are used for the reinitialization described above (i.e., the same starting conditions in every year). Runs start on 1 November and end on 31 March in the Northern Hemisphere and start on 1 May and end on 30 November in the Southern Hemisphere. The long-term change in the chlorine loading of the stratosphere is considered by multiplying the $\mathrm{Cl}_{\mathrm{y}}, \mathrm{HCl}$ and $\mathrm{ClONO}_{2}$ values by a number obtained by dividing the equivalent effective stratospheric chlorine (EESC; Newman et al., 2007) of the given year by the EESC of the year 2000.

Figure 15 shows the vortex-averaged mixing ratios at $46 \mathrm{hPa}$ simulated by Polar SWIFT in the Northern Hemisphere at the end of the winter compared to the mixing ratios obtained from MLS ozone data. Note that the date used in the plot differs for every year, since the date of the breakup of the polar vortex is different in every year. The dates are given in Table 4. Figure 16 shows the same for the Southern Hemisphere and on 1 October. Both the magnitude and the interannual variability of the MLS measurements are reproduced well by the Polar SWIFT model runs in the Northern Hemisphere. The interannual variability is larger and reproduced better in the Northern Hemisphere than in the Southern Hemisphere.

Figure 17 shows the time evolution of vortex averages of $\mathrm{O}_{3}$ and $\mathrm{HCl}$ for the winter 2004/2005 in the Northern Hemisphere. The first column shows the results of the Polar SWIFT model run driven by ATLAS and ERA Interim, the second column the results of the full chemistry model run

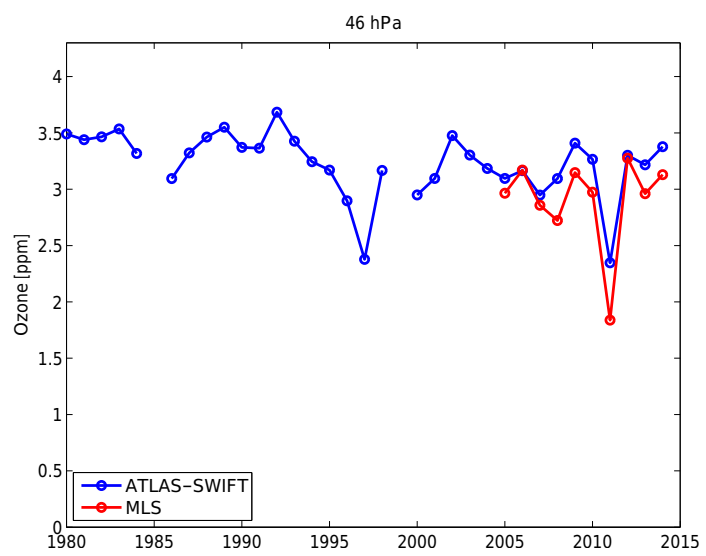

Figure 15. Interannual variability of vortex-averaged ozone mixing ratios in Arctic winter at $46 \mathrm{hPa}$ for Polar SWIFT (blue) and MLS (red), on the last day before vortex breakup. The date differs for different years due to different dates of vortex breakup; see Table 4.

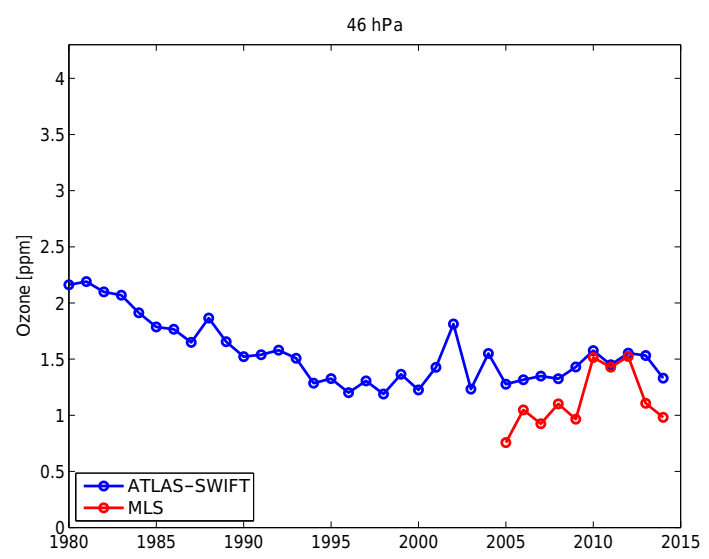

Figure 16. Interannual variability of vortex-averaged ozone mixing ratios in Antarctic spring at $46 \mathrm{hPa}$ on 1 October for Polar SWIFT (blue) and MLS (red). 

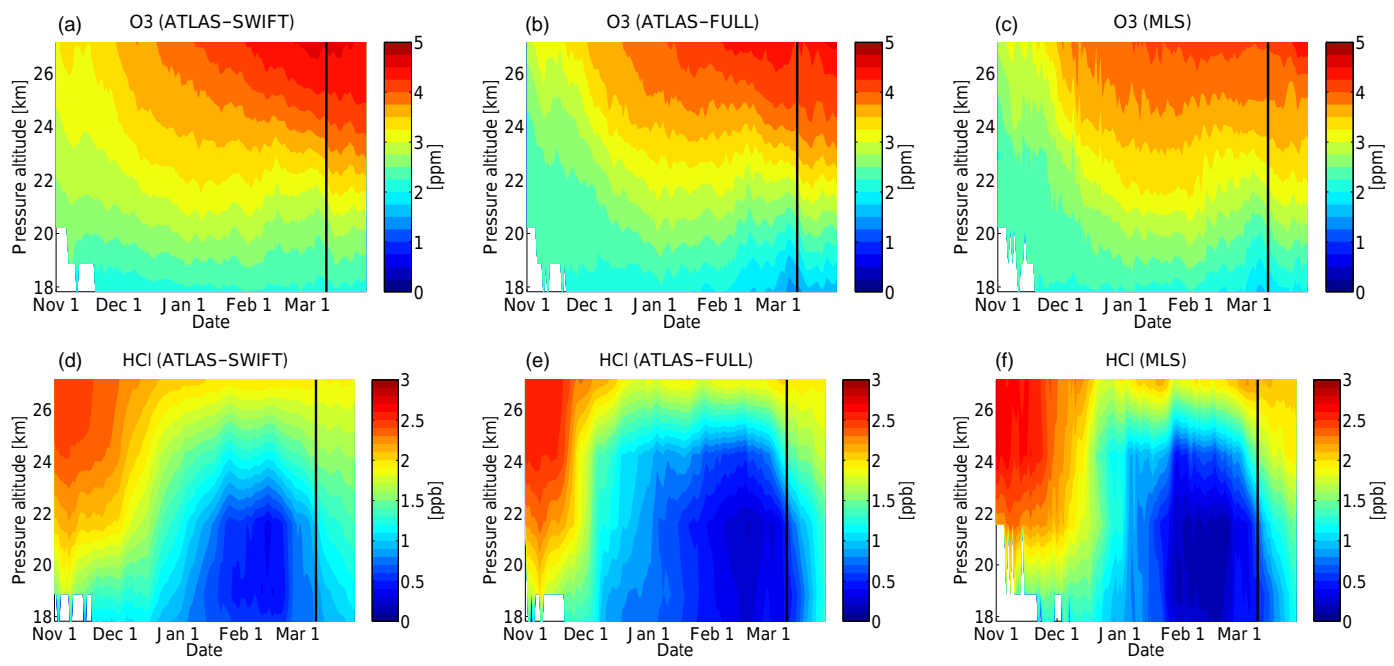

Figure 17. Time evolution of vortex means of $\mathrm{O}_{3}$ and $\mathrm{HCl}$ in the northern hemispheric winter 2004/2005 for Polar SWIFT driven by the ATLAS transport model (a), for the full chemistry model of ATLAS driven by the ATLAS transport model (b) and for MLS satellite measurements $(\mathbf{c})$. The black line marks the approximate breakup date of the vortex.
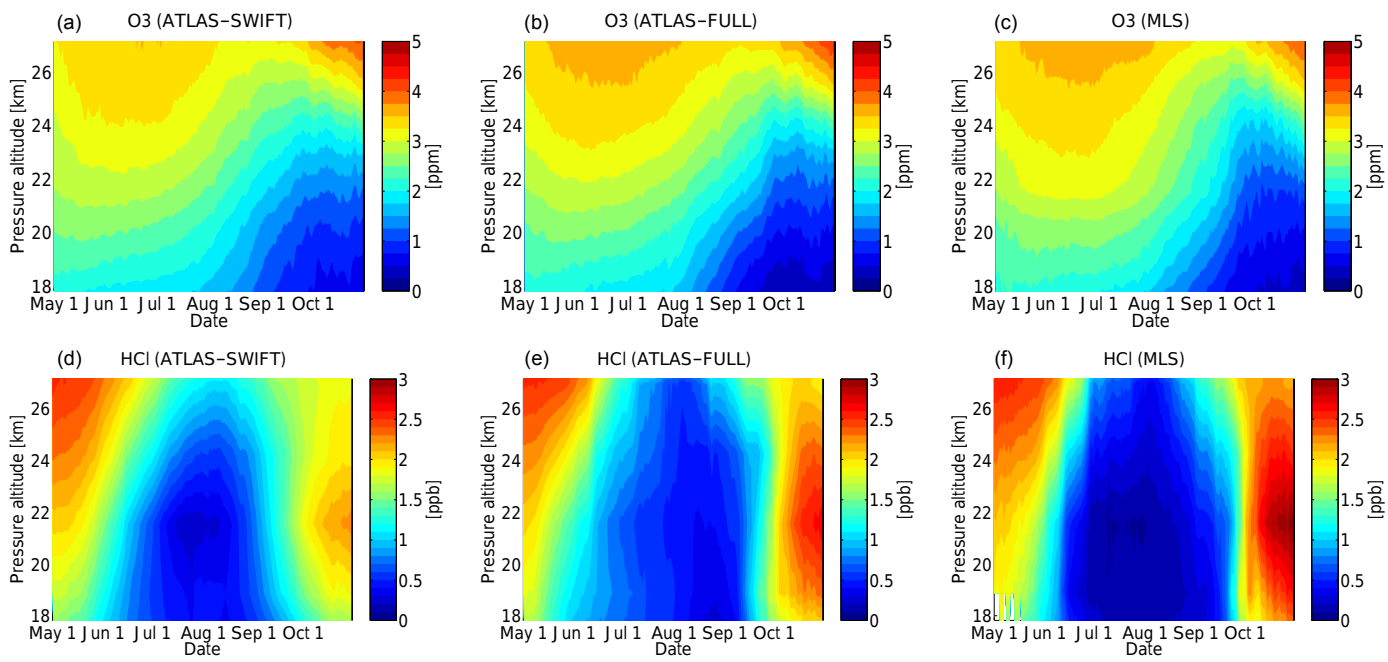

Figure 18. Same as Fig. 17 for the southern hemispheric winter 2006.

of ATLAS and the third column the corresponding measurements of MLS. Figure 18 shows the same for the year 2006 and the Southern Hemisphere. The time evolution of ozone is reproduced well in both hemispheres. Since the long-term ozone climatology used for the initialization of Polar SWIFT is different from the actual measured values, some differences show up in early winter. The evolution of $\mathrm{HCl}$ shows some differences, which are partly caused by the fact that the full ATLAS model has a parameterization that partitions a significant part of $\mathrm{HCl}$ into the liquid phase to overcome a discrepancy between modeled and measured $\mathrm{HCl}$ values (for a detailed discussion, see Wohltmann et al., 2017). Polar SWIFT is always fitted to the total $\mathrm{HCl}$ mixing ratios of ATLAS and has no parameterization for $\mathrm{HCl}$ in the liquid phase. MLS measures $\mathrm{HCl}$ in the gas phase, and consequently, the figures for the full chemistry model and MLS show $\mathrm{HCl}$ in the gas phase. Hence, some differences between the total $\mathrm{HCl}$ values of Polar SWIFT and the gas phase values of MLS are observed. This is however of secondary importance, since the only variable of Polar SWIFT that is used outside of Polar SWIFT in a GCM is ozone.

\section{Conclusions}

This study presents an update of the Polar SWIFT model for fast calculation of stratospheric ozone depletion in polar winter. The update includes a revised formulation of the system of differential equations, a new training method based on model results of the ATLAS Chemistry and Transport Model 
Table 4. Dates of vortex breakup for Fig. 15.

\begin{tabular}{ll}
\hline Date & Years \\
\hline 1 February & $1981,1987,1991,2001,2004,2006$, \\
& 2012,2013 \\
10 February & 2009 \\
15 February & 2010 \\
1 March & 1984,1989 \\
10 March & 1980,2005 \\
15 March & $1983,1986,1988,1998,2000,2002$, \\
& 2003,2008 \\
24 March & 2011 \\
30 March & $1982,1990,1992,1993,1994,1995$, \\
& $1996,1997,2007,2014$ \\
No stable vortex & 1985,1999 \\
\hline
\end{tabular}

and an extension from a single level to the vertical range in which polar ozone depletion is observed.

The model is validated by comparison to MLS satellite data and the full stratospheric chemistry scheme of the ATLAS model. It is shown that Polar SWIFT is able to successfully simulate the interannual variability and the seasonal change of ozone mixing ratios in the Northern and Southern hemispheres (Figs. 15 to 18).

Polar SWIFT was specifically developed to enable interactions between climate and the ozone layer in climate models. So far, climate models often use prescribed ozone fields, since a detailed calculation of ozone chemistry is computationally very expensive. The computational effort needed is significantly reduced when using the Polar SWIFT model. The computing time for a complete winter simulated by Polar SWIFT is on the order of a fraction of a second on a single processor core, while the computational effort for the detailed chemistry model of ATLAS is on the order of several days per winter on 50 cores on current machines.

Polar SWIFT models the response of ozone to temperature changes and changes in the chlorine loading well, since care has been taken to represent the underlying chemical and physical processes in the model equations. This is also shown in Figs. 15 to 18. As far as possible, the equations are derived by mathematical derivation, but note that some model equations are derived by empirically finding parameterizations that closely fit the training data set, since no closed equation can be derived for them. Bromine, methane, water vapor and some effects of $\mathrm{HNO}_{3}$ are not variable in the model equations, which limits the ability of the model to respond to changes in these species and should be kept in mind.

Code availability. The source code is available on the AWIForge repository (https://swrepol.awi.de/). Access to the repository is granted on request under the given correspondence address. If required, the authors will give support for the implementation of SWIFT.
Competing interests. The authors declare that they have no conflict of interest.

Acknowledgements. This work was supported by the BMBF under the FAST-O3 project in the MiKliP framework programme (FKZ 01LP1137A) and in the MiKliP II programme (FKZ 01LP1517E). This research has received funding from the European Community's Seventh Framework Programme (FP7/2007-2013) under grant agreement no. 603557 (StratoClim). We thank ECMWF for providing reanalysis data.

The article processing charges for this open-access publication were covered by a Research Centre of the Helmholtz Association.

Edited by: Fiona O'Connor

Reviewed by: two anonymous referees

\section{References}

Cariolle, D. and Déqué, M.: Southern hemisphere medium-scale waves and total ozone disturbances in a spectral general circulation model, J. Geophys. Res., 91, 10825-10846, 1986.

Cariolle, D. and Teyssèdre, H.: A revised linear ozone photochemistry parameterization for use in transport and general circulation models: multi-annual simulations, Atmos. Chem. Phys., 7, 21832196, https://doi.org/10.5194/acp-7-2183-2007, 2007.

Cariolle, D., Lasserre-Bigorry, A., Royer, J.-F., and Geleyn, J.-F.: A general circulation model simulation of the springtime Antarctic ozone decrease and its impact on mid-latitudes, J. Geophys. Res., 95, 1883-1898, 1990.

Dee, D. P., Uppala, S. M., Simmons, A. J., Berrisford, P., Poli, P., Kobayashi, S., Andrae, U., Balmaseda, M. A., Balsamo, G., Bauer, P., Bechtold, P., Beljaars, A. C. M., van de Berg, L., Bidlot, J., Bormann, N., Delsol, C., Dragani, R., Fuentes, M., Geer, A. J., Haimberger, L., Healy, S. B., Hersbach, H., Hólm, E. V., Isaksen, L., Kållberg, P., Köhler, M., Matricardi, M., McNally, A. P., Monge-Sanz, B. M., Morcrette, J.-J., Park, B.-K., Peubey, C., de Rosnay, P., Tavolato, C., Thépaut, J.-N., and Vitart, F.: The ERA-Interim reanalysis: configuration and performance of the data assimilation system, Q. J. Roy. Meteorol. Soc., 137, 553597, 2011.

Eyring, V., Shepherd, T. G., and Waugh, D. W.: SPARC CCMVal Report on the Evaluation of Chemistry-Climate Models, SPARC Report No. 5, http://www.sparc-climate.org/ publications/sparc-reports/ (last access: 4 July 2017), 2010.

Eyring, V., Arblaster, J. M., Cionni, I., Sedlacek, J., Perlwitz, J., Young, P. J., Bekki, S., Bergmann, D., Cameron-Smith, P., Collins, W. J., Faluvegi, G., Gottschaldt, K.-D., Horowitz, L. W., Kinnison, D. E., Lamarque, J.-F., Marsh, D. R., SaintMartin, D., Shindell, D. T., Sudo, K., Szopa, S., and Watanabe, S.: Long-term ozone changes and associated climate impacts in CMIP5 simulations, J. Geophys. Res., 118, 5029-5060, https://doi.org/10.1002/jgrd.50316, 2013.

Hanisco, T. F.: Stratospheric chemistry and composition/HO $/ \mathrm{H}_{\mathrm{x}}$, in: vol. 5, Encyclopedia of Atmospheric Sciences, edited by: Holton, 
J. R., Curry, J. A., and Pyle, J. A., Academic Press, Elsevier, 2174-2180, 2003.

Hanisco, T. F., Lanzendorf, E. J., Wennberg, P. O., Perkins, K. K., Stimpfle, R. M., Voss, P. B., Anderson, J. G., Cohen, R. C., Fahey, D. W., Gao, R. S., Hintsa, E. J., Salawitch, R. J., Margitan, J. J., McElroy, C. T., and Midwinter, C.: Sources, Sinks, and the Distribution of $\mathrm{OH}$ in the Lower Stratosphere, J. Phys. Chem. A, 105, 1543-1553, 2001.

Hanson, D. and Mauersberger, K.: Laboratory studies of the nitric acid trihydrate: Implications for the south polar stratosphere, Geophys. Res. Lett., 15, 855-858, 1988.

Hsu, J. and Prather, M. J.: Stratospheric variability and tropospheric ozone, J. Geophys. Res., 114, D06102, https://doi.org/10.1029/2008JD010942, 2009.

IPCC: Climate Change 2013: The Physical Science Basis, in: Contribution of Working Group I to the Fifth Assessment Report of the Intergovernmental Panel on Climate Change, edited by: Stocker, T. F., Qin, D., Plattner, G.-K., Tignor, M. M. B., Allen, S. K., Boschung, J., Nauels, A., Xia, Y., Bex, V., and Midgley, P. M., Cambridge University Press, Cambridge, UK and New York, USA, 2013.

Jöckel, P., Tost, H., Pozzer, A., Brühl, C., Buchholz, J., Ganzeveld, L., Hoor, P., Kerkweg, A., Lawrence, M. G., Sander, R., Steil, B., Stiller, G., Tanarhte, M., Taraborrelli, D., van Aardenne, J., and Lelieveld, J.: The atmospheric chemistry general circulation model ECHAM5/MESSy1: consistent simulation of ozone from the surface to the mesosphere, Atmos. Chem. Phys., 6, 50675104, https://doi.org/10.5194/acp-6-5067-2006, 2006.

Kreyling, D., Wohltmann, I., Lehmmann, R., and Rex, M.: The extrapolar SWIFT model: Fast Stratospheric ozone chemistry for global climate models, Geophys. Model Dev. Discuss., submitted, 2017.

Lait, L. R.: An alternative form for potential vorticity, J. Atmos. Sci., 51, 1754-1759, 1994.

McLinden, C. A., Olsen, S. C., Hannegan, B. J., Wild, O., and Prather, M. J.: Stratospheric ozone in 3-D models: a simple chemistry and the cross-tropopause flux, J. Geophys. Res., 105, 14653-14665, 2000.

Newman, P. A., Daniel, J. S., Waugh, D. W., and Nash, E. R.: A new formulation of equivalent effective stratospheric chlorine (EESC), Atmos. Chem. Phys., 7, 4537-4552, https://doi.org/10.5194/acp-7-4537-2007, 2007.

Nowack, P. J., Abraham, N. L., Maycock, A. C., Braesicke, P., Gregory, J. M., Joshi, M. M., Osprey, A., and Pyle, J. A.: A large ozone-circulation feedback and its implications for global warming assessments, Nat. Clim. Change, 5, 41-45, 2015.

Rex, M., Salawitch, R. J., Deckelmann, H., von der Gathen, P., Harris, N. R. P., Chipperfield, M. P., Naujokat, B., Reimer, E., Allaart, M., Andersen, S. B., Bevilacqua, R., Braathen, G. O., Claude, H., Davies, J., De Backer, H., Dier, H., Dorokhov, V., Fast, H., Gerding, M., Godin-Beekmann, S., Hoppel, K., Johnson, B., Kyrö, E., Litynska, Z., Moore, D., Nakane, H., Parrondo, M. C., Risley Jr., A. D., Skrivankova, P., Stübi, R., Viatte, P., Yushkov, V., and Zerefos, C.: Arctic winter 2005: Implications for stratospheric ozone loss and climate change, Geophys. Res. Lett., 33, L23808, https://doi.org/10.1029/2006GL026731, 2006.
Rex, M., Kremser, S., Huck, P., Bodeker, G., Wohltmann, I., Santee, M. L., and Bernath, P.: Technical Note: SWIFT - a fast semi-empirical model for polar stratospheric ozone loss, Atmos. Chem. Phys., 14, 6545-6555, https://doi.org/10.5194/acp14-6545-2014, 2014.

Roeckner, E., Brokopf, R., Esch, M., Giorgetta, M., Hagemann, S., Kornblueh, L., Manzini, E., Schlese, U., and Schulzweida, U.: Sensitivity of Simulated Climate to Horizontal and Vertical Resolution in the ECHAM5 Atmosphere Model, J. Climate, 19, 3771-3791, 2006.

Sander, S. P., Abbatt, J., Barker, J. R., Burkholder, J. B., Friedl, R. R., Golden, D. M., Huie, R. E., Kolb, C. E., Kurylo, M. J., Moortgat, G. K., Orkin, V. L., and Wine, P. H.: Chemical kinetics and photochemical data for use in atmospheric studies, Evaluation Number 17, JPL Publication 10-06, Jet Propulsion Laboratory, California Institute of Technology, Pasadena, http://jpldataeval.jpl.nasa.gov (last access: 4 July 2017), 2011.

Thompson, D. W. J. and Solomon, S.: Interpretation of Recent Southern Hemisphere Climate Change, Science, 296, 895-899, 2002.

Waters, J. W., Froidevaux, L., Harwood, R. S., Jarnot, R. F., Pickett, H. M., Read, W. G., Siegel, P. H., Coeld, R. E., Filipiak, M. J., Flower, D. A., Holden, J. R., Lau, G. K., Livesey, N. J., Manney, G. L., Pumphrey, H. C., Santee, M. L., Wu, D. L., Cuddy, D. T., Lay, R. R., Loo, M. S., Perun, V. S., Schwartz, M. J., Stek, P. C., Thurstans, R. P., Chandra, K. M., Chavez, M. C., Chen, G.-S., Boyles, M. A., Chudasama, B. V., Dodge, R., Fuller, R. A., Girard, M. A., Jiang, J. H., Jiang, Y., Knosp, B. W., LaBelle, R. C., Lam, J. C., Lee, K. A., Miller, D., Oswald, J. E., Patel, N. C., Pukala, D. M., Quintero, O., Scaff, D. M., Snyder, W. V., Tope, M. C., Wagner, P. A., and Walch, M. J.: The Earth Observing System Microwave Limb Sounder (EOS MLS) on the Aura satellite, IEEE T. Geosci. Remote, 44, 1075-1092, 2006.

Wohltmann, I. and Rex, M.: The Lagrangian chemistry and transport model ATLAS: validation of advective transport and mixing, Geosci. Model Dev., 2, 153-173, https://doi.org/10.5194/gmd-2153-2009, 2009.

Wohltmann, I., Lehmann, R., and Rex, M.: The Lagrangian chemistry and transport model ATLAS: simulation and validation of stratospheric chemistry and ozone loss in the winter 1999/2000, Geosci. Model Dev., 3, 585-601, https://doi.org/10.5194/gmd-3585-2010, 2010.

Wohltmann, I., Wegner, T., Müller, R., Lehmann, R., Rex, M., Manney, G. L., Santee, M. L., Bernath, P., Suminska-Ebersoldt, O., Stroh, F., von Hobe, M., Volk, C. M., Hösen, E., Ravegnani, F., Ulanovsky, A., and Yushkov, V.: Uncertainties in modelling heterogeneous chemistry and Arctic ozone depletion in the winter 2009/2010, Atmos. Chem. Phys., 13, 3909-3929, https://doi.org/10.5194/acp-13-3909-2013, 2013.

Wohltmann, I., Lehmann, R., and Rex, M.: A quantitative analysis of the reactions involved in stratospheric polar ozone depletion, Atmos. Chem. Phys. Discuss., https://doi.org/10.5194/acp-201766, in review, 2017. 